\title{
A Genetically Defined Morphologically and Functionally Unique Subset of 5-HT Neurons in the Mouse Raphe Nuclei
}

\author{
Vera Kiyasova, ${ }^{1,2,3 *}$ Sebastian P. Fernandez, ${ }^{1,2,3 *}$ Jeanne Laine, ${ }^{1,2,3}$ Lea Stankovski, ${ }^{1,2}$ Aude Muzerelle, ${ }^{1,2,3}$ \\ Stephane Doly,,$^{1,2,3}$ and Patricia Gaspar ${ }^{1,2,3}$ \\ ${ }^{1}$ Inserm, UMR-S 839, ${ }^{2}$ Université Pierre et Marie Curie, and ${ }^{3}$ Institut du Fer à Moulin, 75005 Paris, France
}

\begin{abstract}
Heterogeneity of central serotonin (5-HT) raphe neurons is suggested by numerous lines of evidence, but its genetic basis remains elusive. The transcription factor Pet1 is required for the acquisition of serotonergic identity in a majority of neurons in the raphe nuclei. Nevertheless, a subset of 5-HT neurons differentiates in Pet1 knock-out mice. We show here that these residual 5-HT neurons outline a unique subpopulation of raphe neurons with highly selective anatomical targets and characteristic synaptic differentiations. In Pet1 knock-out mice, 5-HT innervation strikingly outlines the brain areas involved in stress responses with dense innervation to the basolateral amygdala, the paraventricular nucleus of the hypothalamus, and the intralaminar thalamic nuclei. In these regions, 5-HT terminals establish asymmetric synaptic junctions. This target selectivity could not be related to altered growth of the remaining 5-HT neurons, as indicated by axon tracing and cell culture analyses. The residual 5-HT axon terminals are functional with maintained release properties in vitro and in vivo. The functional consequence of this uneven distribution of 5-HT innervation on behavior was characterized. Pet1 knock-out mice showed decreased anxiety behavior in novelty exploration and increased fear responses to conditioned aversive cues. Overall, our findings lead us to propose the existence of Pet1-dependent and Pet1-resistant 5-HT neurons targeting different brain centers that might delineate the anatomical basis for a dual serotonergic control on stress responses.
\end{abstract}

\section{Introduction}

Serotonin $(5-\mathrm{HT})$ modulates a wide range of brain functions ranging from autonomic control and emotional responses to cognitive processes (Jacobs and Azmitia, 1992; Lucki, 1998). The extent to which these diverse physiological roles are served by different anatomical systems is unclear. Several characteristics of the brain 5-HT neurons emphasize their broad modulatory function, namely their diffuse projections, and their capacity to release amines at nonsynaptic sites (Fuxe et al., 2007; Descarries et al., 2010). However, other features, such as the existence of synaptic contacts and the demonstration of a tight temporal control, suggest that the amine can exert more discrete actions at specific brain loci (Kirby et al., 1995; Adell et al., 1997; Dieudonné and Dumoulin, 2000; Varga et al., 2009).

Mounting evidence for heterogeneity of the 5-HT neurons in the raphe suggests that different raphe subnuclei serve specific functions. Raphe 5-HT neurons are organized into two main rostrocaudal subdivisions that are further split into subnuclei, with different morphologies and anatomical projections (Imai et

\footnotetext{
Received Aug. 5, 2010; revised Nov. 5, 2010; accepted Dec. 17, 2010.

This research was funded by INSERM, the Université Pierre et Marie Curie, the European Commission (FP7-health2007-A-201714), and the Agence Nationale pour la recherche (ANR605-neur-046). The Fondation pour la Recherche Médicale funds S.P.F. We thank Evan Deneris for the gift of the Pet1 knock-out and Pet $1{ }^{\mathrm{CRE}}$ mice, Gord Fishell for the gift of RCE:LoxP mice, Silvina Diaz for her help with behavioral tests, and Cornelius Gross and Luc Maroteaux for their critical reading of the manuscript. Francine Côté, Jean François Brunet, Marion Wassef, and James Briscoe are acknowledged for the gift of probes.

*V.K. and S.P.F. contributed equally to this work.

Correspondence should be addressed to Patricia Gaspar, Inserm U839 Institut du Fer à Moulin, 17 rue du Fer à Moulin, 75005 Paris, France. E-mail: patricia.gaspar@inserm.fr.

DOI:10.1523/JNEUROSCI.4080-10.2011

Copyright $\odot 2011$ the authors $\quad 0270-6474 / 11 / 312756-13 \$ 15.00 / 0$
}

al., 1986; Abrams et al., 2004). Different morphological properties of 5-HT axons have also been described (Hornung et al., 1990; Mamounas et al., 1991), as well as distinct synaptic properties (Descarries et al., 2010). Further neurochemical heterogeneity complexified this anatomical partitioning, showing that neuropeptides (Lacoste et al., 2006; Fu et al., 2010) or an unusual subtype of the vesicular glutamate transporter, Vglut3, are present in subsets of 5-HT neurons (Herzog et al., 2004; Hioki et al., 2010).

Genetic and developmental studies may provide clues to understand the basis for the heterogeneity among 5-HT neurons. Raphe neurons are generated from different rhombomeres (Cordes, 2005; Jensen et al., 2008), but a common transcriptional pathway leading to 5-HT neuron differentiation was identified. Pet1, a transcription factor of the ETS family, is particularly important for determining the identity of 5-HT neurons in the raphe; it is expressed in the raphe neurons (Hendricks et al., 1999; Pfaar et al., 2002; Lillesaar et al., 2007), and its ortholog, FEV, is expressed in the human raphe (Iyo et al., 2005). Petl drives the expression of genes involved in 5-HT identity, namely the biosynthetic enzyme, tryptophan hydroxylase (Tph2), and the 5-HT plasma membrane transporter (Scl6a4) (Hendricks et al., 2003, Liu et al., 2010). However, a contingent of raphe neurons acquires a 5-HT phenotype in the Pet1-knock-out mice (Hendricks et al., 2003; Scott et al., 2005), suggesting that this may reveal a cryptic heterogeneity of the 5-HT raphe neurons.

We show here that the residual 5-HT neurons in Pet1 knockout mice have highly selective targets in the brain, outlining brain areas involved in central autonomic control and in stress responses. These terminals form asymmetric synaptic junctions 
and are capable of releasing 5-HT. This indicated that residual 5-HT neurons in Pet1 knock-out mice comprise a well defined anatomical entity in terms of brain targets and synaptic connectivity that transcends classic anatomical subdivisions of the raphe. Based on behavioral observations showing reduced anxiety responses but increased fear learning in the Pet1 knock-out mice, we hypothesize that a differential requirement for Pet1 reveals two different 5-HT subsystems underlying the dual control of stress responses by 5 -HT.

\section{Materials and Methods}

Animals. Experiments were conducted in compliance with the standard ethical guidelines (European community guidelines and French Agriculture and Forestry Ministry guidelines for handling animals-decree 87849). The Petl knock-out mouse line (gift from Evan Deneris, Case Western Reserve University, Cleveland, $\mathrm{OH}$ ) was maintained on a C57BL6 genetic background. Heterozygote Pet1 $+/-$ females were mated with Pet $1+/-$ or Pet $1-/-$ males to produce mixed litters. Littermates were used in all experiments, and both Pet $1+/+$ and Pet $1+/-$ served as controls, since no differences of 5-HT levels between the two genotypes were found, neither in the initial study (Hendricks et al., 2003) nor in the present analyses. Genotyping of the progeny was done by PCR analysis of tail DNA as described previously (Hendricks et al., 2003).

The Pet ${ }^{\text {cre }}$ mouse line (gift from Evan Deneris) was intercrossed with RCE:loxP reporter mice (gift from Gord Fishell, Smilow Research Center, New York University, New York, NY), to direct the expression of EGFP to Pet1+ neurons.

Immunohistochemistry. Adult and postnatal day 5 (P5) mice were anesthetized (pentobarbital, $25 \mathrm{mg} / \mathrm{kg}$ and xylazine, $5 \mathrm{mg} / \mathrm{kg}$ ), perfused transcardially with $4 \%$ paraformaldehyde in $0.12 \mathrm{~m}$ phosphate buffer (PB), pH 7.4. Embryonic day 15 (E15) embryos were extracted from the uterus, anesthetized on ice, and perfused with paraformaldehyde. Brains were removed from the skull and postfixed overnight in the same fixative. After cryoprotection (PB with $30 \%$ sucrose for $48 \mathrm{~h}$ ) serial $52-\mu \mathrm{m}$-thick coronal sections were made on a freezing microtome and collected in PB.

Alternate series were used for immunostaining and for in situ hybridization (ISH). Sections were washed in PBS, then in PGTx (PBS with $0.2 \%$ gelatin and $0.25 \%$ Triton X-100). Sections were incubated overnight at room temperature with the following antisera: anti-5-HT (rabbit polyclonal 1/10,000; Sigma; rat monoclonal 1/50; Millipore Bioscience Research Reagents), anti-5-HTT (1/3000; rabbit polyclonal, Calbiochem), anti-Tph (mouse monoclonal 1/1000; Sigma), anti-Vmat2 (rabbit polyclonal 1/1000; Millipore Bioscience Research Reagents), and anti-GFP (rabbit polyclonal 1/5000, Invitrogen).

For bright-field microscopy, the sections were incubated for $1.5 \mathrm{~h}$, at room temperature, in biotinylated goat anti-rabbit antibody $(1 / 200$; Vector Laboratories) or mouse antiserum (1/200; GE Healthcare) followed by streptavidin-peroxidase complex (1/400; GE Healthcare) $(1.5 \mathrm{~h})$ and reacted in a solution containing $1 \%$ diaminobenzidine and $0.005 \% \mathrm{H}_{2} \mathrm{O}_{2}$ in $0.1 \mathrm{~m}$ Tris buffer, $\mathrm{pH}$ 7.6. Sections were mounted on SuperFrost slides, dried, dehydrated in graded ethanols, cleared in xylene, and coverslipped in Eukitt. For fluorescence microscopy, sections were incubated for $2 \mathrm{~h}$ at room temperature either with goat anti-rabbit coupled to CY3 (1/200; Jackson ImmunoResearch) or with goat anti-rabbit coupled to Alexa488 (1/200, Invitrogen); sections were counterstained $10 \mathrm{~min}$ in bisbenzimide $(10 \mu \mathrm{g} / \mathrm{ml}$; Sigma $)$ and mounted in mowiol-Dabco $(25 \mathrm{mg} / \mathrm{ml})$.

In situ hybridization. Specific antisense RNA probes for Tph1 and Tph2 (gift from Dr. F. Côté, UMR 7091 CNRS/UPMC, Paris, France), 5-HTT and Vglut3 (gift from Dr. S. El Mestikawy, Inserm U952, Paris, France) and Pet1 Gata3 and Lmx1b (gift from Dr. J. F. Brunet, IBENS, Paris, France) genes were used for in situ hybridization analyses. DIG probes were synthesized with a labeling kit according to the manufacturer's instructions (Roche). Frozen sections were rinsed $3 \times 5 \mathrm{~min}$ in PBS + $0.1 \%$ Tween (PBTw), dehydrated in graded ethanol $(25,50,75$, and $100 \%, 5 \mathrm{~min})$, treated in $100 \%$ ethanol with $1 \% \mathrm{H}_{2} \mathrm{O}_{2}(1 \mathrm{~h})$, rehydrated in graded ethanol $(100,75,50,25 \%)$, rinsed in PBTw $2 \times 5$ min, and treated with proteinase $\mathrm{K}(10 \mu \mathrm{g} / \mathrm{ml})$ for $1 \mathrm{~min}$. Sections were incubated in $\mathrm{PBTw}+$ glycine $(2 \mathrm{mg} / \mathrm{ml})$, rinsed in PBTw, and postfixed in a mixture of $4 \%$ paraformaldehyde, $0.2 \%$ glutaraldehyde, and $0.1 \%$ Tween $(20$ min), followed by a rinse in PBTw. Tissue sections were hybridized at $70^{\circ} \mathrm{C}$ overnight with the DIG-labeled probes diluted $1 / 100$ in hybridization buffer ( $50 \%$ formamide, $5 \times$ SSC, $50 \mu \mathrm{g} / \mathrm{ml}$ yeast RNA, $50 \mu \mathrm{g} / \mathrm{ml}$ heparin, $0.1 \%$ Tween). The next day, sections were sequentially washed in $50 \%$ formamide, $5 \times$ SSC, $0.1 \%$ Tween buffer $\left(1.5 \mathrm{~h}\right.$ at $\left.70^{\circ} \mathrm{C}\right), 0.5 \mathrm{M}$ $\mathrm{NaCl}, 10 \mathrm{~mm}$ Tris $\mathrm{pH} 7.6,0.1 \%$ Tween buffer ( $1 \mathrm{~h}$ at room temperature), and $50 \%$ formamide, $2 \times$ SSC, $0.1 \%$ Tween buffer $\left(1.5 \mathrm{~h}\right.$ at $\left.70^{\circ} \mathrm{C}\right)$. For immunological detection of DIG-labeled hybrids, sections were first blocked in TBST solution ( $80 \mathrm{~g}$ of $\mathrm{NaCl}, 2 \mathrm{~g}$ of $\mathrm{KCl}, 250 \mathrm{ml}$ of $1 \mathrm{M}$ Tris-HCl, $\mathrm{pH} 7.6,0.1 \%$ Tween) with $10 \%$ of normal goat serum for $2 \mathrm{~h}$. Sections were then incubated overnight at $4^{\circ} \mathrm{C}$ in a solution containing sheep anti-DIG-alkaline phosphatase-conjugated Fab fragments (Roche) diluted $1 / 2000$ in TBST buffer plus $1 \%$ NGS and levamisole $(5 \mathrm{mg} / 10$ $\mathrm{ml})$. The third day, sections were washed $2 \times 15 \mathrm{~min}$ in TBST buffer, 30 min in NTMT buffer (100 mm NaCl, $100 \mathrm{~mm}$ Tris-HCl, pH 9.5, $50 \mathrm{~mm}$ $\mathrm{MgCl}_{2}, 0.1 \%$ Tween 20). The alkaline phosphatase chromogen reaction was performed in NTMT buffer containing $100 \mathrm{mg} / \mathrm{ml}$ nitroblue tetrazolium (Roche) and $50 \mathrm{mg} / \mathrm{ml}$ 5-bromo-4-chloro-3-indolyl phosphate (Roche) at room temperature for 5-6 h and stopped with Tris-EDTA buffer. Sections were mounted on glass slides, dried, dehydrated in graded ethanol solutions, cleared in xylene, and coverslipped with Eukitt.

Combined in situ hybridization and immunohistochemistry. Vglut3, TPH2, Lmx1b, and Gata3 antisense RNA probes were revealed with in situ hybridization (ISH) as described above. After the reaction was stopped with Tris-EDTA buffer, the sections were rinsed several times in PBS and PGTx and processed for immunohistochemistry. The Vglut3 ISH detection was combined with TPH immunohistochemistry. TPH2, Lmxlb, and Gata3 ISH was combined with anti-GFP immunohistochemistry. The reaction was revealed in a solution containing $1 \%$ diaminobenzidine, $0.005 \% \mathrm{H}_{2} \mathrm{O}_{2}$ in $0.1 \mathrm{M}$ Tris buffer, $\mathrm{pH}$ 7.6. Sections were mounted on SuperFrost slides, dried, dehydrated in graded ethanol solutions, cleared in xylene, and coverslipped in Eukitt.

Raphe cultures. E12.5 embryos were collected from matings of Pet $1+/-$ mice. Embryos were individually dissected in buffered HEPES and the rostral raphe was cut into $200 \mu \mathrm{m}$ explants. Explants were placed onto polylysine/laminin-coated 8 well ibiTreat plastic microscopy chambers (Ibidi), in DMEM medium to which methylcellulose $(0.4 \%)$, BSA $(0.01 \%)$, penicillin $(1 \%)$, glutamine $(10 \mathrm{~mm})$, and glucose $(0.07 \%)$ were added. Explants were cultured for $4 \mathrm{~d}$ at $37^{\circ} \mathrm{C}$. They were fixed in $4 \%$ paraformaldehyde and $15 \%$ sucrose for $1 \mathrm{~h}$, and rinsed in PBS. Immunocytochemistry using 5-HT (1/10,000 rabbit polyclonal, Sigma), $\beta$-tubulin (1/2000 mouse polyclonal, Sigma), and GAP43 (1/200 chicken polyclonal, Millipore Bioscience Research Reagents) antiserum was performed as described above.

Image acquisition. Bright-field histology images were captured with a Cool Snap FX camera fitted to a Leica DM RD microscope using $10 \times /$ 0.40 and $20 \times / 0.70$ objectives (magnification/numerical aperture) or to a Zeiss Axiophot $(10 \times / 0.32$ and $20 \times / 0.5$ objectives). Fluorescence microscopic images were acquired with a Leica DM 6000B system using a $20 \times / 0.70$ oil objective. Stitching of multiple micrographs into a single frame was done with MetaMorph software. The same settings of brightness/contrast were used within a given experiment comprising control and Pet1 knock-out mice.

Confocal images were obtained using a DM IRE2 Leica TCS SP2 microscope with $60 \times / 1.32$ oil, $100 \times / 1.40$ oil objective lenses. Alexa 488 and Cy3 were excited with the appropriate excitation wavelength (488 and $543 \mathrm{~nm}$ ) and scanned with emission filters selected to optimally separate fluorescence (510/530 bandpass filter for Alexa 488 and 560/600 bandpass filter for $\mathrm{Cy} 3$ ). Each image was acquired with the laser intensity adjusted to prevent saturation. Thickness of the confocal section was set at $0.4 \mu \mathrm{m}$ at a resolution of $1024 \times 1024$ pixels. Images were further processed in Adobe Photoshop CS2, for brightness/contrast and background corrections.

Quantification. Confocal images were copied to 8-bit RGB digital format and analyzed with ImageJ software. To avoid subjective biases, all the pictures were number coded. The procedure comprised: subtraction of the background (rollerball), normalization, and extraction of a binary image after applying a fixed threshold level within a given experiment. 
For fiber density estimates, we measured the area occupied by the fibers on the binary image within a circular mask of a standard diameter of 22 $\mu \mathrm{m}^{2}$. Estimates of density per area/ per case were based on the averaging of values obtained from three different fields. Data were processed with Graph Pad Prism5 statistics software, using nonparametric Student's $t$ test and expressed as average pixel $/ \mu \mathrm{m}^{2}$. Results were considered as significantly different if $p<0.05\left(^{*}\right), p<0.01\left(^{* *}\right)$, and $p<0.005\left(^{* * *}\right)$.

Preembedding immunoperoxidase electron microscopy. Six adult mice $(2$ Pet $1+/+, 1$ Pet $1+/-$, and 3 Pet $1-/-)$ were anesthetized $(60 \mathrm{mg} / \mathrm{kg}$ pentobarbital) and transcardially perfused with $100 \mathrm{ml}$ of $3.5 \%$ acrolein in $0.1 \mathrm{M} \mathrm{PB}, \mathrm{pH} 7.4$, followed by $4 \%$ paraformaldehyde in the same buffer. Brains were dissected out, postfixed $1-2 \mathrm{~h}$ in $4 \%$ paraformaldehyde at $4^{\circ} \mathrm{C}$, and cut with a vibratome into $80-\mu \mathrm{m}$-thick coronal sections. After PBS rinsing $(4 \times 20 \mathrm{~min})$ and $30 \mathrm{~min}$ quenching in $0.3 \% \mathrm{NaBH}_{4}$, freefloating sections were sequentially incubated at room temperature: $1 \mathrm{~h}$ in a blocking PBS solution containing 5\% normal rabbit serum and $0.2 \%$ gelatin; overnight in the same solution containing anti-5-HTT serum (1/1000 or 1/5000); and $2 \mathrm{~h}$ in $1 / 200$ biotinylated rabbit anti-goat serum (Vector Laboratories). A standard avidin-biotin complex revelation (Vectastain Elite 1/200, Vector) was applied, using 0.05\% diaminobenzidine and $0.005 \% \mathrm{H}_{2} \mathrm{O}_{2}$ in $0.1 \mathrm{M} \mathrm{PB}$.

The specificity of the polyclonal antibody raised in goat against the last C-terminal 20 aa of the human 5-HTT protein has been characterized previously (Pickel and Chan, 1999), we further noted the absence of labeling after processing 5-HTT knock-out mouse brain sections.

After $2 \% \mathrm{OsO}_{4}$ postfixation, sections were dehydrated in graded acetone including $2 \%$ uranyl acetate staining during the $70 \%$ acetone step, and flat-embedded in Epon. Selected areas were glued on a resin block, and $70 \mathrm{~nm}$ thin sections were serially collected on membrane-coated slot grids. Observations were made on a Philips CM120 electron microscope, micrographs were taken with a SIS Morada digital camera and measures were taken with the associated iTEM software.

For ultrastructural analysis, terminals were identified as 5-HTTimmunostained axonal enlargements containing aggregated synaptic vesicles, associated with one or several mitochondria. Synaptic membrane specializations were defined as local straightening of apposed membranes with a slight widening of the intermembrane space, and thickening of presynaptic and/or postsynaptic membrane. They were identified on at least two adjacent sections. The cross-sectional area of the three largest profiles of given varicosity was measured from serial digital micrographs $(\times 46,000)$, to calculate the mean varicosity size.

Retrograde tracing of raphe neurons. Adult female mice were used for these experiments. Mice were anesthetized with ketamine $(50 \mathrm{mg} / \mathrm{kg})$ and xylazine $(2 \mathrm{mg} / \mathrm{kg})$ and fixed in a stereotaxic apparatus. Stereotaxically guided injections were made through holes in the dorsal surface of the cranium. Glass capillary tubes were pulled (HEKA pipette puller PIP5) and tips broken to $40 \mu \mathrm{m}$ diameter. Capillaries were filled with Fluorogold 4\% in PB pH 7.4, or with Dextran Alexa Fluor 568 (Invitrogen). Iontophoretic injections of fluorogold were targeted to the lateral amygdala using the following coordinates: $1.58 \mathrm{~mm}$ caudal to the bregma, $3.5 \mathrm{~mm}$ lateral to the midline, and $4.5-4.75 \mathrm{~mm}$ deep from the skull surface. Positive alternative current of $5 \mu \mathrm{A}$ ( $7 \mathrm{~s}$ on/7 $\mathrm{s}$ off) was applied during $13 \mathrm{~min}$. Both iontophoretic and pressure injections $(0.5$ $\mu \mathrm{l}$ during $10 \mathrm{~min}$ ) were used to target the hippocampus (coordinates: $-2.06 \mathrm{~mm}$ caudal to the bregma, $1.5 \mathrm{~mm}$ lateral to the midline, and 2-2.2 $\mathrm{mm}$ deep from the skull surface). Micropipettes were left in place $10 \mathrm{~min}$ before removal to minimize leakage. The stereotaxic coordinates used for these injections were obtained from the atlas (Paxinos and Franklin, 2001) and checked in pilot experiments.

After a $14 \mathrm{~d}$ survival, the animals were perfused and the brains processed as described above. Alternate series were used for examining retrograde tracer labeling alone, or in combination with 5-HT or Tph immunofluorescent staining. Quantitative analyses were done in the cases where the injections were correctly positioned [basolateral amygdala (BLA): $\operatorname{ctrl}=4$ and pet $1-/-=3$; hippocampus: $\operatorname{ctrl}=3$ and pet $1-/-=3]$. One of six sections in the series was analyzed in every case (i.e., 6-7 sections that include the raphe in adults). The back-labeled cells were counted in all the sections and their localization in the raphe subnuclei was plotted on micrographs obtained with a Leica DM RD pho- tomicroscope ( $10 \times / 0.40$ objective), using the UV spectrum filter (340 $\mathrm{nm}$ excitation wave length). Colabeling with 5 -HT or Tph was analyzed on consecutive sections and similarly plotted on the micrographs.

5-HT uptake/release and 5-HTT binding to brain synaptosomes. Wholebrain synaptosomes from three Petl knock-out and three control mice (P60) were prepared as described previously (Gray and Whittaker, 1962). Briefly, mice were killed by decapitation and their brains were rapidly $(<10 \mathrm{~min}$ ) dissected out and homogenized in 40 volumes ( $8 \mathrm{ml}$ for a 500 $\mathrm{mg}$ brain) of ice-chilled $0.32 \mathrm{~m}$ sucrose, in a glass homogenizer with a Teflon pestle (Potter-Elvehjem tissue grinder). The homogenates were centrifuged at $1000 \times g$ for $10 \mathrm{~min}\left(4^{\circ} \mathrm{C}\right)$ and the supernatants centrifuged again at $15,000 \times g\left(4^{\circ} \mathrm{C}\right)$ for 30 min to yield the crude synaptosomal pellet (P2). 5-HT uptake was measured using six concentrations of [ $\left.{ }^{3} \mathrm{H}\right] 5$-HT (3.125-200 nM). Brain synaptosomes were added to tubes containing $120 \mathrm{~mm} \mathrm{NaCl}, 20 \mathrm{~mm}$ Tris $\mathrm{HCl}, 5 \mathrm{~mm} \mathrm{KCl}, 1.2 \mathrm{~mm} \mathrm{MgSO}_{4}, 2.5$ $\mathrm{mm} \mathrm{CaCl} 2,10 \mathrm{~mm}$ glucose, $1 \mathrm{~mm}$ ascorbic acid, and $0.1 \mathrm{~mm}$ pargyline. $\left[{ }^{3} \mathrm{H}\right] 5-\mathrm{HT}$ uptake was allowed to occur for $10 \mathrm{~min}$ at $37^{\circ} \mathrm{C}$. Nonspecific $\left[{ }^{3} \mathrm{H}\right] 5-\mathrm{HT}$ uptake was defined as the accumulation in the presence of 100 nM paroxetine and was subtracted from total uptake. Immersing the tubes in ice-cold buffer was followed by rapid filtration through Whatman GF/B filters terminated the process. Release assays were performed in 96-well ( $1.2 \mathrm{ml})$ plates. Each well was preloaded with the following: 50 $\mu \mathrm{l}$ of buffer with increasing concentrations of releasing agent $[(+)-3,4$ methylenedioxymethamphetamine (MDMA): $0.1 \mathrm{~nm} ; 1 \mathrm{nM} ; 10 \mathrm{~nm} ; 100$ $\mathrm{nM} ; 1 \mu \mathrm{M} ; 10 \mu \mathrm{M}$ ] in duplicate. Before release, pellet $\mathrm{P} 2$ was resuspended in buffer and allowed to uptake $\left[{ }^{3} \mathrm{H}\right] 5-\mathrm{HT}(10 \mathrm{~nm} ; 24 \mathrm{Ci} / \mathrm{mmol})$ during $30 \mathrm{~min}\left(37^{\circ} \mathrm{C}\right)$. The reaction was initiated by addition of $450 \mu \mathrm{l}$ of synaptosome preparation and stopped after $30 \mathrm{~min}$ by rapid vacuum filtration over GF/B filters. Radioactivity was measured using liquid scintillation counting. For saturation binding assay on synaptosomes membrane fraction, varied from 0.6 to $20 \mathrm{~nm}$. Nonspecific binding was determined in the presence of $100 \mathrm{~nm}$ paroxetine and was subtracted from total binding. For $\left[{ }^{3} \mathrm{H}\right]$ citalopram $(80 \mathrm{Ci} / \mathrm{mmol}$; PerkinElmer $)$ binding, whole-brain synaptosomes were homogenized in ice-cold buffer containing $50 \mathrm{~mm}$ Tris, $120 \mathrm{~mm} \mathrm{NaCl}$, and $5 \mathrm{~mm} \mathrm{MgCl}_{2}$, $\mathrm{pH}$ 7.4. The homogenate was centrifuged for $20 \mathrm{~min}$ at $15,000 \times \mathrm{g}$. The pellet was then resuspended and centrifuged under the same condition three times. $\left[{ }^{3} \mathrm{H}\right]$ citalopram $(2 \mathrm{~nm})$ and paroxetine $(0.01 \mathrm{~nm}$ to $1 \mu \mathrm{M})$ were added to the final suspension $(0.6 \mathrm{mg} / \mathrm{ml})$. Binding data were analyzed using the iterative nonlinear fitting software Graph Pad Prism 4.0 to estimate dissociation constants $\left(K_{\mathrm{D}}\right)$ and maximum number of sites $\left(B_{\max }\right)$.

Behavioral experiments. Behavioral experiments were conducted using adult mice of either gender weighing 30-35 g. Animals were housed in groups of four per cage with ad libitum access to food and water, and maintained in a controlled environment $\left(20-23^{\circ} \mathrm{C}, 45-\right.$ $55 \%$ relative humidity) with a $12 / 12 \mathrm{~h} \mathrm{light/dark}$ cycle (light on at 08:00 A.M.). Animals did not undergo more than one behavioral assay except for elevated plus maze and open field, where the same batch of animals were used.

Novelty-driven exploration. Animals were submitted to three noveltybased paradigms: the elevated plus maze, the open field, and the noveltysuppressed feeding. The elevated plus maze consisted of two open arms $(30 \times 5 \mathrm{~cm})$ and two closed arms $(30 \times 5 \times 15 \mathrm{~cm})$ made of Plexiglas connected by an open central platform $(5 \times 5 \mathrm{~cm})$ and elevated $40 \mathrm{~cm}$ from ground level. Animals were placed in the center of the apparatus facing an open arm and allowed to explore the maze for $5 \mathrm{~min}$. Immediately after completing the elevated plus maze, animals were placed in an open field $(50 \times 50 \times 30)$ made of black Plexiglas, and allowed to freely explore it for $5 \mathrm{~min}$. All sessions were videotaped by cameras positioned above the mazes, and the number of arm entries and time spent in arms were scored using ODLog v2.3 (Macropod Software). The noveltysuppressed feeding test was conducted in a plastic box of $37 \times 57 \times 10$ $\mathrm{cm}$, under direct white light illumination (200 lux), and with floors covered with $2 \mathrm{~cm}$ of sawdust. Mice were food deprived for $18 \mathrm{~h}$ and then placed in the box corner. Latency to approach and eat a single food pellet located in the center of the box was measured using a stopwatch. Cutoff time was $5 \mathrm{~min}$. Finally, locomotor activity was evaluated in lowluminosity circular arenas equipped with four light beams placed at $90^{\circ}$ 

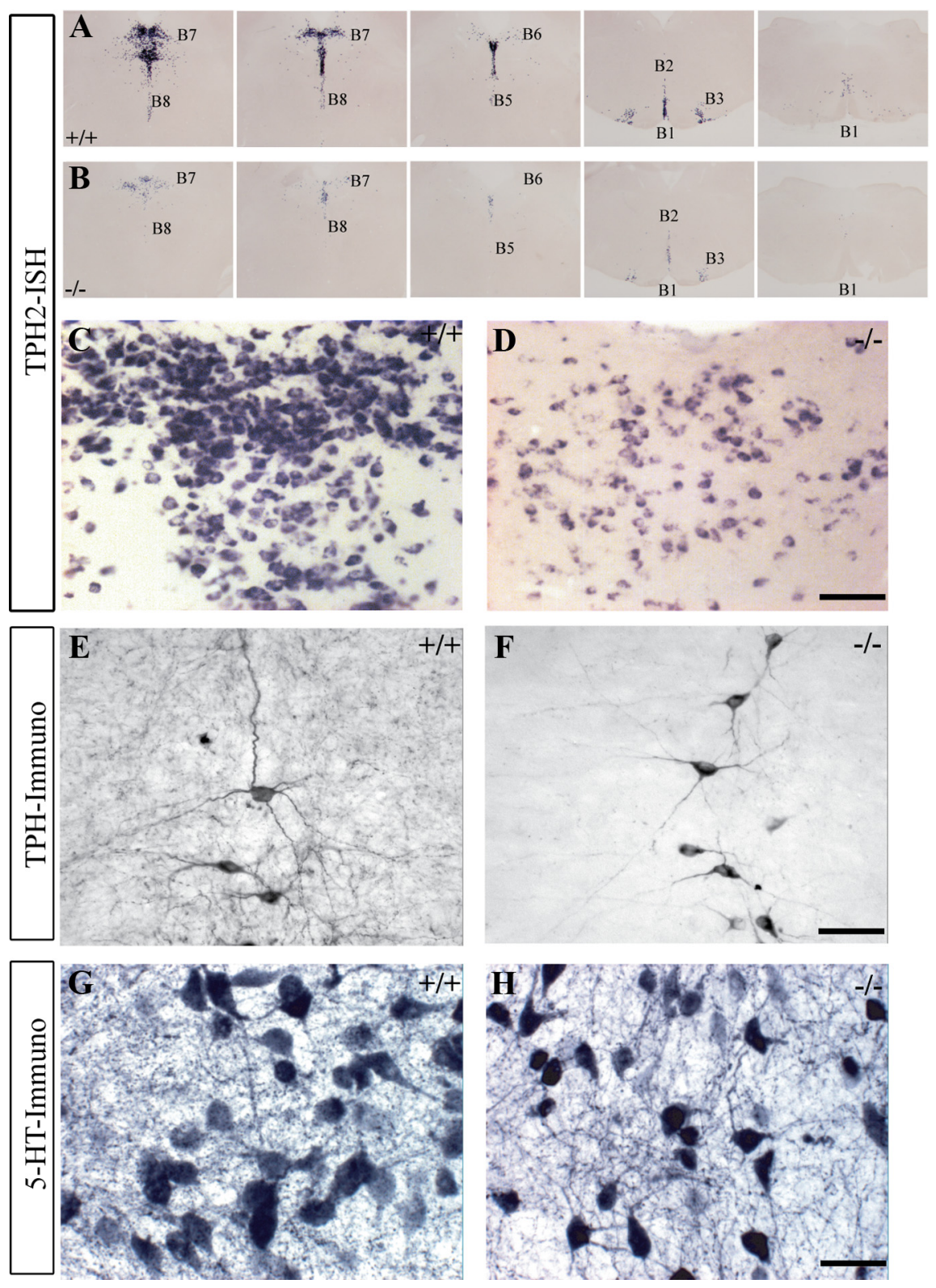

Figure 1. Distribution and morphology of Tph2-positive neurons in the raphe of Pet1 knock-out mice (Pet1-/-). $A, B$, Tph2 mRNA expression on serial coronal sections through the raphe (B1 to B9 cell groups). A subpopulation of 5 -HT-synthesizing neurons remains throughout the 5 -HT cell groups in Pet1-/- C, D, Higher-magnification micrographs of the dorsal raphe (B7) show reduced level of Tph2 mRNA per cell in Pet1-I-(D), compared to controls $(\boldsymbol{C}) . \boldsymbol{E}, \boldsymbol{F}$, Tph immunohistochemistry, in the B2 cell group, shows normal dendrite morphology and no difference in the staining intensity. $\mathbf{G}, \boldsymbol{H}, 5-\mathrm{HT}$ immunocytochemistry shows a similar intensity of staining in dorsal raphe neurons of control and Pet1 $-I-$. Illustrations are from experiments where control and Pet1 - / - littermates were processed in parallel. Scale bars: $\mathbf{C}, \boldsymbol{D}, 200 \mu \mathrm{m} ; \boldsymbol{E}, \boldsymbol{F}, 100 \mu \mathrm{m} ; \boldsymbol{G}, \boldsymbol{H}, 50 \mu \mathrm{m}$.

from each other (Imetronic). Total numbers of beam breaks were used as indication of ambulatory activity.

Fear conditioning. Fear conditioning was performed in behavioral boxes (Imetronic), and procedures were adapted from Crestani et al. (1999). For context conditioning, animals were placed into the chamber and allowed to habituate for $3 \mathrm{~min}$, followed by three consecutive foot shocks $(0.5 \mathrm{~mA}, 50 \mathrm{~Hz}, 1 \mathrm{~s})$ separated by $1 \mathrm{~min}$. Testing occurred $24 \mathrm{~h}$ after, in the same chamber, and freezing was scored for a total of $8 \mathrm{~min}$. For delay conditioning, a tone cue $(1000 \mathrm{~Hz}, 80 \mathrm{~dB}, 10 \mathrm{~s})$ was paired and coterminated with the shocks. After 3 min habituation to the chamber, three pairings were given at 3 min intervals. Retention sessions occurred $24 \mathrm{~h}$ after in a modified context (new tactile, visual, and olfactory cues), where freezing was measured for $3 \mathrm{~min}$ without tone, and $7 \mathrm{~min}$ in the presence of the tone. Protocol for trace fear conditioning was similar to delay protocol, except that a $3 \mathrm{~s}$ lag (trace) was introduced between the tone and the shock. In all cases, sessions were recorded and freezing was manually scored. Freezing was defined as complete absence of movement, except for respiration. Data were expressed as percentage time freezing.

Dexfenfluramine-stimulated c-Fos expression and corticosterone release. Animals were habituated to intraperitoneal injections for 4 consecutive days. On day 5 , animals were divided into D-fenfluramine and saline groups. Dexfenfluramine $\mathrm{HCl}$ (Tocris Bioscience) was dissolved in saline and administered intraperitoneally in a dose of $10 \mathrm{mg} / \mathrm{kg}$ to adult male control and Pet1 knock-out mice. For c-Fos immunohistochemistry experiments, $1 \mathrm{~h}$ after injection, animals were injected with a mixture of pentobarbital $(25 \mathrm{mg} / \mathrm{kg})$ and xylazine $(5$ $\mathrm{mg} / \mathrm{kg}$ ) and transcardially perfused with $4 \%$ paraformaldehyde in $0.12 \mathrm{M} \mathrm{PB}, \mathrm{pH}$ 7.4. Brains were dissected out, postfixed $24 \mathrm{~h}$ in $4 \%$ paraformaldehyde at $4^{\circ} \mathrm{C}$, and cut with a vibratome into $50-\mu \mathrm{m}$-thick coronal serial sections. Immunohistochemistry was performed as described above. Primary antibody used was antic-Fos rabbit polyclonal 1/2000 (Santa Cruz Biotechnology); incubation was performed overnight at $4^{\circ} \mathrm{C}$; secondary antibody was biotinylated goat anti-rabbit (1/200; Vector Laboratories). For corticosterone experiments, animals were killed $1 \mathrm{~h}$ after injection and trunk blood was collected into heparinized tubes. Blood was centrifuged at $1000 \times g$ at $4^{\circ} \mathrm{C}$ for $10 \mathrm{~min}$, and plasma samples were recovered and stored at $-80^{\circ} \mathrm{C}$ until use. Corticosterone concentration was measured according to the manufacturer's instructions (Assays Designs). Statistical analysis was performed using GraphPad Prism v5 software (GraphPad).

\section{Results}

\section{Characterization of 5-HT neurons in the raphe of Pet1 \\ knock-out mice}

Previous morphological analyses in Pet1 knock-out mice showed that raphe neurons are generated normally but that a majority fail to acquire a serotonergic phenotype and remain in an arrested state of differentiation (Hendricks et al., 2003), a subset of these neurons being eliminated (Scott et al., 2005). However, a subpopulation of 5-HT neurons differentiates in the raphe of Pet1 knock-out mice and was estimated to be in the order of $20-30 \%$ of the 5 -HT neuron population in wild-type mice (Fig. 1). These neurons expressed all the genes linked to the 5-HT phenotype, such as tryptophan hydroxylase (Tph) (Fig. 1), amino acid decarboxylase (Aadc), the 5-HT transporter (5-HTT, Slc6a4), and the vesicular monoamine transporter (Vmat2, Slc18a2), albeit with reduced expression levels (Hendricks et al., 2003). These raphe neurons also express a set of genes involved in the genetic programming of 5-HT cell fate, other than Pet1. Using a mouse line where GFP expression is driven by cre recombinase under the Pet1 promoter, we found Lmx1b and Gata3 gene expression in a majority of the Pet1-Cre progeny (supplemental 
Fig. S1, available at www.jneurosci.org as supplemental material). Lmxlb and Gata3 showed comparable expression patterns in the raphe of control and Pet1 knock-out mice (supplemental Fig. S1, available at www.jneurosci.org as supplemental material), indicating that these genes continue to be expressed independently of Pet 1 and could contribute to serotonin identity. This is in line with observations of maintained Gata3 expression in Pet $1^{\mathrm{cKO}}$ (Liu et al., 2010).

The residual 5-HT neurons in Pet1 knock-out mice were distributed uniformly in the B1-B9 cell groups (Fig. $1 A, B$ ) and displayed dendritic morphologies comparable to controls (Fig. $1 E, F$ ). Density estimates in the B7 cell group showed that $25 \%$ of the normal 5-HT raphe neurons were maintained in Pet1 knock-out mice (Pet1 knockout $=28.67 \pm 1.2$; controls $=114 \pm 5.6$, neurons $/ 100 \mu \mathrm{m}^{2}$ ), confirming previous observations (Hendricks et al., 2003). We examined which Tph isoforms are expressed. Tph2 is the dominant isoform in the brain, but Tph1 has also been found in a raphe subpopulation during postnatal development (Nakamura et al., 2006), or in adaptive pathological circumstances such as restraint stress in rats (Abumaria et al., 2008). Tph1 expression was detected with RT-PCR in the raphe in control and Pet1 knock-out mice. However, in situ hybridization with specific Tph1 and Tph2 probes showed only Tph2 expression in both genotypes. Tph2 gene expression was reduced in Petl knock-out mice (Fig. $1 C, D)$, contrasting with a lack of downregulation of Tph (Fig. 1E,F) or 5-HT (Fig. $1 G, H)$ immunolabeling.

Vglut3-positive neurons appeared to be relatively spared in the raphe of Pet1 knockout mice (supplemental Fig. S2C,D, available at www.jneurosci.org as supplemental material) (Petl knock-out $=75.8 \pm 7.0$; controls $=110.8 \pm 6.1$, Vglut $3+$ neurons $/$ $100 \mu \mathrm{m}^{2}$ ), suggesting that Vglut3 may be a useful label of the residual 5-HT neurons in Pet1 knock-out mice. However, double labeling showed that only a fraction of the Vglut3-positive neurons in the raphe were serotonergic (supplemental Fig. S2E,F, available at www.jneurosci.org as supplemental material).

Overall, these observations indicated that the residual 5-HT neurons in Pet1 knock-out mice have a normal morphology and capacity of 5-HT synthesis.

\section{Serotonergic axons target specific brain regions in Pet 1 knock-out mice}

Next, we analyzed the axonal projections of 5-HT raphe neurons in Pet1 knock-out mice using 5-HT and 5-HTT immunostaining on serial brain sections. In the control brains, 5-HT and 5-HTTZl, zona incerta.
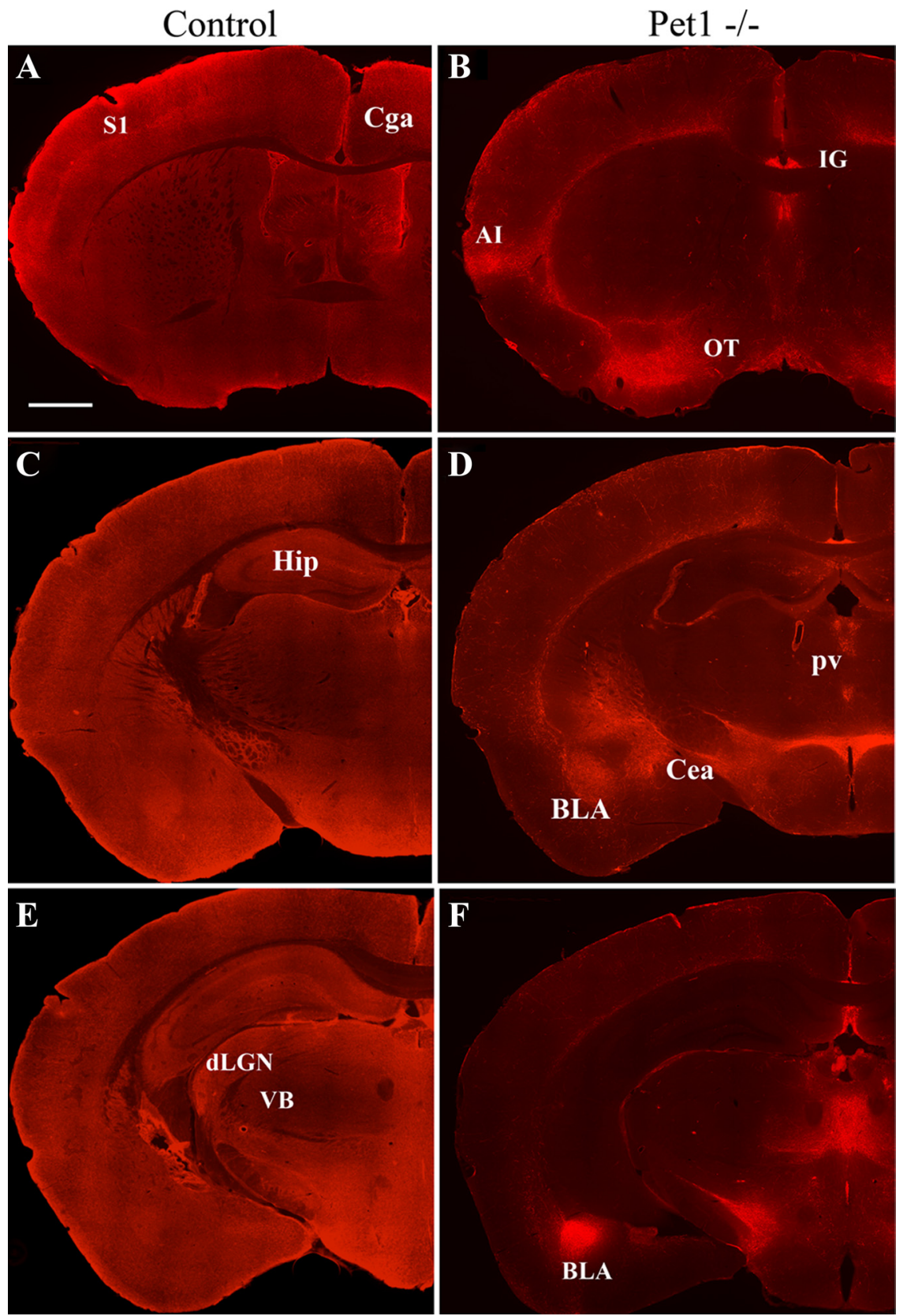

Figure 2. Sparing of 5-HT innervation in selected brain regions in the Pet1 knock-out mice. 5-HT immunohistochemistry is shown on brain sections from different rostrocaudal levels in control $(\boldsymbol{A}, \boldsymbol{C}, \boldsymbol{E})$ and Pet1 $-/-(\boldsymbol{B}, \boldsymbol{D}, \boldsymbol{F})$ littermates. The images were assembled from multiple high-magnification micrographs. In control mice, 5 -HT innervation is widely and almost uniformly distributed, whereas in Pet1 - / - , 5-HT axons are strikingly preserved in the indusium griseum $(\boldsymbol{B})$, the basolateral nucleus of the amygdala $(\boldsymbol{D}, \boldsymbol{F})$, the paraventricular hypothalamic nucleus $(\boldsymbol{D})$, and the medial thalamic nuclei $(\boldsymbol{F})$. In contrast, 5 -HT innervation is almost completely depleted in most cortical areas $(\boldsymbol{B}-\boldsymbol{F})$, in the caudate $(\boldsymbol{B})$, the hippocampus $(\boldsymbol{D}, \boldsymbol{F})$, and the anterior hypothalamus $(\boldsymbol{D}, \boldsymbol{F})$. CeA, Central amygdala; (ga, anterior cingulate cortex; $C P$, caudate nucleus; dLGN, dorsal lateral geniculate nucleus; Hip, hippocampus; IG, indusium griseum; IMD, intermediodorsal nucleus of the thalamus; $\mathrm{OT}$, olfactory tubercle; $\mathrm{S}$, primary somatosensory cortex; $\mathrm{VB}$, ventrobasal nucleus of thalamus;

immunoreactive axon terminals were widely distributed in all brain regions with regional differences in the density of terminal innervation (Fig. $2 A, C, E$ ) as described in the rat brain (Lidov et al., 1980). Surprisingly, in Pet1 knock-out brains, 5-HT- and 5-HTT-labeled axons did not show a uniform reduction, but were concentrated in a few specific areas (Fig. $2 B, D, F$ ) in the forebrain, diencephalon, and brainstem. To evaluate the consistency of these observations, the density of labeled axon terminals was evaluated in 10 representative areas (Fig. $3 A, B$ ). This allowed 
A
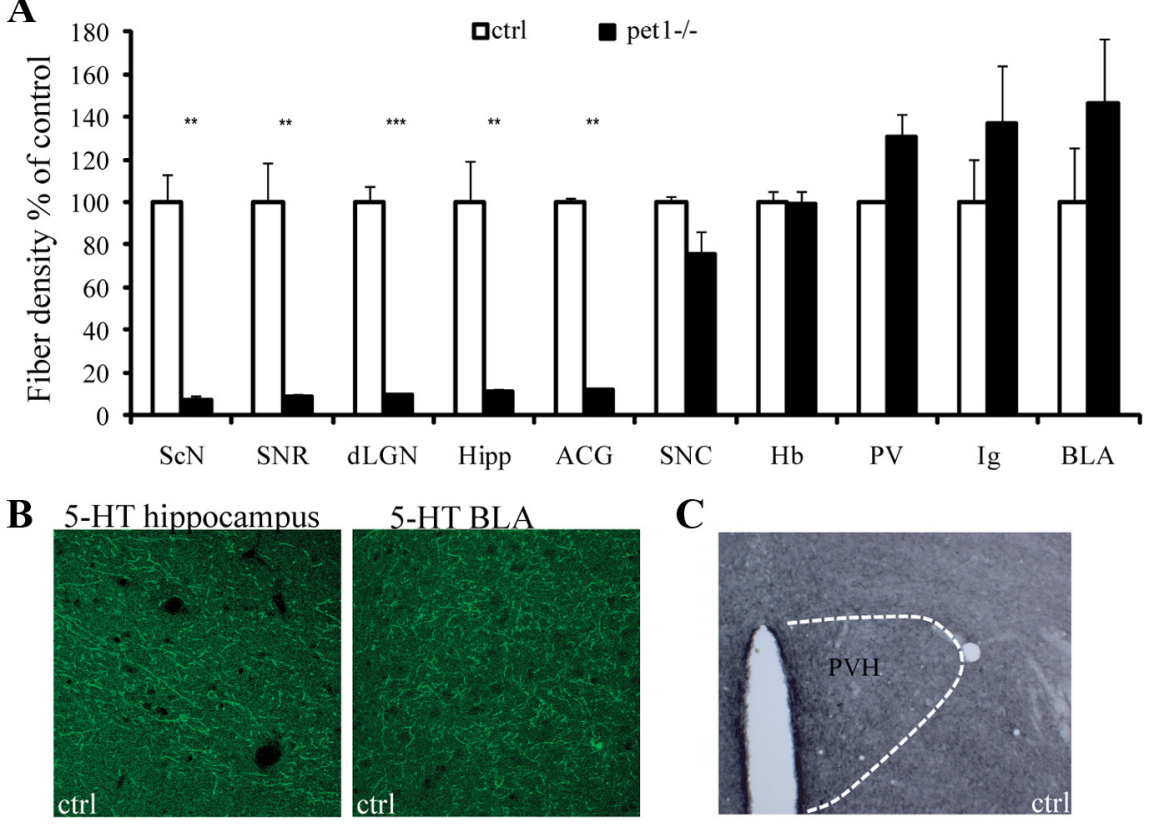

C
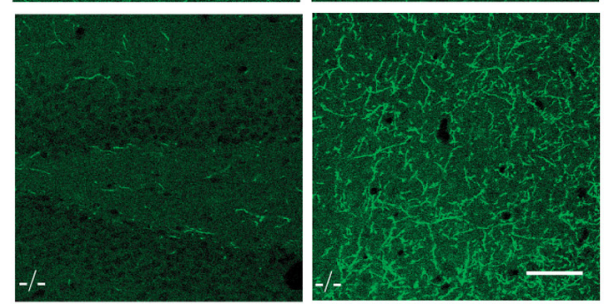

Figure 3. Quantification of the regional density of 5-HT terminals. A, Axon densities were estimated as pixels/ $\mu \mathrm{m}^{2}$ in each of the 10 structures analyzed ( $n=4 /$ group). Fiber density in Pet1 - / - are expressed as percentage of density in controls (ctrl). In the histogram, brain areas are ranked according to the residual density of 5-HT fibers in Pet1 - / - Data are presented as mean \pm SEM, Student's $t$ test, ${ }^{* *} p<0.01$ and ${ }^{* *} p<0.005$. ScN, Suprachiasmatic nucleus of hypothalamus; SNR, substantia nigra pars reticulata; dLGN, dorsal lateral geniculate nucleus; Hip, hippocampus; Cga, anterior cingulate cortex; SNC, substantia nigra pars compacta; $\mathrm{Hb}$, habenula; IG, indusium griseum. $\boldsymbol{B}$, Examples of the confocal images $(0.40 \mu \mathrm{m})$ in the hippocampus and the BLA that were used for the quantitative analyses of the densities of $5-\mathrm{HT}$ innervation in controls and Pet1 $-/-$. C, Distribution of 5 -HT-immunolabeled terminals in the hypothalamus of control and Pet1 $-/-$. Note the high density of fibers through the whole structure in controls, whereas in the Pet $1-/-$ only the paraventricular nucleus receives a dense 5 -HT innervation.

the identification of brain regions that have an almost complete depletion of 5-HT-labeled axons ( $>80 \%$ reduction) versus areas in which the density of 5-HT-labeled axons is comparable to controls (Fig. $3 A, B$ ). Almost identical results were obtained in counts for 5-HTT immunolabeling (data not shown). In two areas, the BLA and the indusium griseum, a nonsignificant increase in the density of labeling was observed; however, this could be attributed to an increase in the size of single axon terminal boutons (see below, ultrastructural analysis) rather than to an increase in the number of terminal boutons. This quantitative analysis, moreover, showed the absence of a correlation between the densities of terminal innervation in controls versus Pet 1 knockout mice, strengthening the notion that the distribution of 5-HTpositive axons does not reflect a uniform depletion of the 5-HT axon terminals.

The areas in which 5-HT terminals remained in Pet1 knockout mice showed no particular topographic proximity to the raphe: some structures that are close to the raphe, such as the tectum, were entirely depleted, whereas distal brain areas, such as the amygdala, were preserved, indicating a specificity of targeting. Moreover, within a given structure, densely innervated areas were juxtaposed to areas in which 5-HT innervation was absent (Fig. 2). Several regions of the brain exemplify this characteristic distribution. In the hypothalamus, the suprachiasmatic nucleus and infundibular nuclei were almost entirely depleted, whereas the paraventricular nucleus of the hypothalamus (PVH) received a normally dense innervation (Fig. $2 D, 3 C$ ). In the thalamus, the central and midline thalamic nuclei received a normal innervation, whereas the sensory relay nuclei, such as the ventrobasal or the lateral geniculate nucleus, were entirely depleted (Fig. $2 F$ ). In the amygdala, parts of the central and basolateral nucleus received a dense innervation (Fig. 2F). Dense 5-HT innervation continued into the extended amygdala structures, such as the bed nucleus of the stria terminalis (pars lateralis). In the cerebral cortex, the infralimbic and agranular insular cortex received a normal innervation, whereas the medial prefrontal, the cingulate, and the entorhinal cortices were almost completely depleted of 5-HT axons. In the brainstem, the ventral part of the periaqueductal gray (PAG), the nucleus parabrachialis, the nucleus of the solitary tract, the ventrolateral medulla, and the nucleus ambiguus showed preserved innervations (supplemental Figs. S3, S4, available at www.jneurosci.org as supplemental material).

Overall, the distribution of the 5-HT axon terminals in Pet1 knock-out mice strikingly outlined a functionally connected network of brain structures involved in central neurovegetative control (Saper, 1995, 2002) and stress responses (Ulrich-Lai and Herman, 2009). Remarkably, 5-HT innervation in Pet1 knock-out mice was entirely depleted from brain areas involved in higher integrating functions, such as the prefrontal cortex, thalamic relay nuclei, and hippocampus.

\section{Normal growth of 5-HT neurons in Pet1 knock-out mice}

The specific distribution of the serotonergic axon terminals in the Pet1 knock-out brains suggests that an anatomical subset of raphe 5-HT neurons is unmasked in the mutant mice. However, another interpretation is that lack of Pet1 modifies axon growth properties of the residual raphe 5-HT neurons, or causes a secondary reorganization of their growth. To distinguish between these possibilities, we analyzed the development of raphe 5-HT neurons at different stages, in vitro and in vivo. Raphe explants from Pet 1 knock-out and control embryos at E12 were grown on laminin-coated plastic dishes for $4 \mathrm{~d}$. Total axon outgrowth, visualized with $\beta$-tubulin immunostaining, was unchanged. The number of 5-HT-labeled neurites was considerably reduced in Pet1 knock-out raphe explants (Fig. 4A, $B$ ), but their length (Pet1 knock-out $=1009 \pm 70 \mu \mathrm{m}, n=9$; control $=1050 \pm 70 \mu \mathrm{m}, n=$ 15 ; mean \pm SEM), the morphology of their growth cones, and expression of GAP43, a phosphoprotein associated with axon growth in the 5-HT neurons (Donovan et al., 2002), were unchanged (Fig. 4C,D). We further examined the fiber tracts in vivo at E15 and P5. The trajectory of the ascending 5-HT axons was 
Control
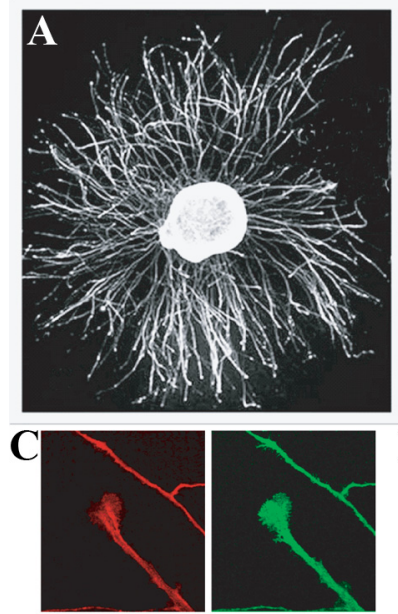

-HT

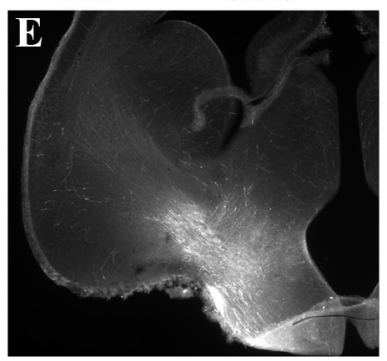

Pet1-/-
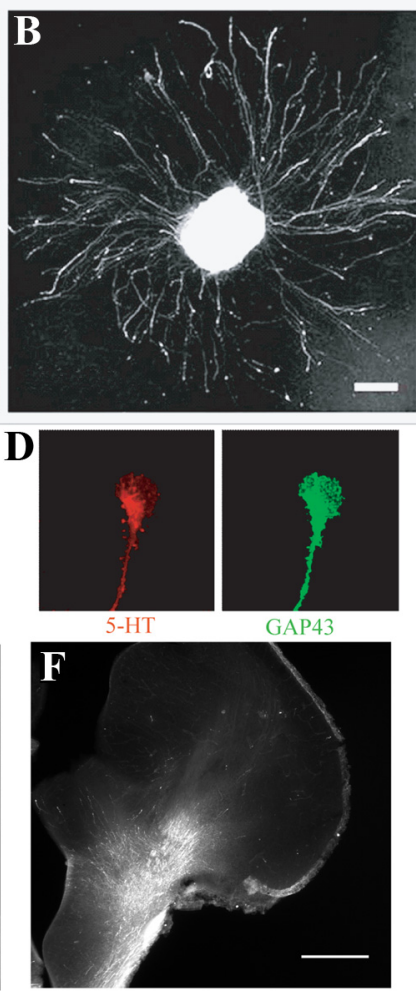

Figure 4. Growth characteristics of 5-HT neurons in vitro and in vivo. $A, B$, Raphe explants (E12 + 4DIV) from control and Pet1 - / - were immunolabeled with anti-5-HT antiserum. The number of 5 -HT-labeled axons growing from the explants is significantly reduced in Pet1 - /-, but the length of neurites is similar in both genotypes. Scale bar, $200 \mu \mathrm{m}$. C, D, Growth cones of raphe neurons (E12.5 + 4DIV) have similar morphologies in control and Pet1 - / - after 5-HT immunolabeling with (red) and GAP 43 (green) antibodies. $\boldsymbol{E}, \boldsymbol{F}$, The morphology and general trajectory of ascending 5 -HT axons in the medial forebrain bundle is unchanged in Pet1-/(F) E15 embryos, compared to controls (E). Scale bar, $400 \mu \mathrm{m}$.

unchanged in Petl knock-out mice, with a majority of the ascending 5-HT fiber tracts following the medial forebrain (Fig. $4 E, F)$ and the anterior cingulate bundles. 5-HT raphe neurons had already reached their most distal telencephalic target, the prefrontal cortex, at E15 in Pet1 knock-out and control mice (supplemental Fig. S5, available at www.jneurosci.org as supplemental material). Moreover, the selective distribution of 5-HT axons in the PVH, intralaminar thalamic nuclei, and BLA was already visible at $\mathrm{P} 5$ in Pet 1 knock-out mice, indicating that these are primary targets of 5-HT neurons rather than a secondary reorganization in Pet1 knock-out mice.

Overall, these observations support the notion that the growth and pathfinding properties of the raphe neurons that acquire a 5-HT phenotype in the Pet1-knock-out mice are not affected.

\section{Normal topographic distribution of raphe projections to forebrain}

To further examine whether targeting of raphe neurons is normal, we performed retrograde tracing experiments. Fluorescent tracers were injected in two forebrain areas: the hippocampus, which shows the most severe 5-HT depletion, and the basolateral amygdala, in which 5-HT innervation is partly spared. After amygdala injections (Fig. 5C) retrogradely labeled neurons were found mostly in the dorsal raphe nuclei in both control and Pet 1 knock-out mice (Fig. 5A,B). There was no significant reduction in the number of these neurons (Pet $1-/-=11.6 \pm$
0.7 neurons; controls $=11.3 \pm 0.3$ neurons; mean \pm SEM on 3 cases). Fifty percent of these retrogradely labeled neurons were Tph immunoreactive in controls, and $30 \%$ were in the Pet1 knock-out mice (Fig. 5D).

After hippocampal injections, back-labeled neurons were found mainly in the median raphe nuclei in both control and Pet1 knock-out mice, but with a consistent reduction in the number of retrogradely labeled neurons in Pet 1 knock-out (Pet1-/- = $4.0 \pm 0.5$ neurons; controls $=10.6 \pm 0.3$ neurons; mean \pm SEM from 3 cases). Moreover, whereas $50 \%$ of the retrogradely labeled neurons were 5-HT labeled in control mice, none were 5-HT labeled in Pet1 knock-out (Fig. 5F).

Overall, these observations indicate that the residual serotonin neurons in Pet1 knock-out mice maintain normal projections and that the general topography of raphe projections is maintained. In contrast, raphe neurons that fail to become serotoninergic in the Pet1 knock-out mice also fail to maintain projections to the forebrain.

\section{5-HT axon terminals form junctional synapses in innervated areas}

Ultrastructural analyses of the serotonergic axon terminals were performed in three structures in which 5-HT innervation is maintained in Pet1 knock-out mice, the BLA, the paraventricular thalamic nucleus (PVT), and the PVH. 5-HTT-immunolabeled axon terminals were analyzed in serially reconstructed sections (supplemental Fig. S6, available at www.jneurosci.org as supplemental material). In Pet1 knock-out mice as in controls, 5-HTTlabeled terminals contained small aggregated clear vesicles, sparse dense core vesicles, and a high density of mitochondria (Fig. 6). In control mice, asymmetrical synapses were observed in $38 \%$ of the labeled boutons in the BLA ( $n=22$, complete series analyzed) (Fig. 6A,B); in the PVT, $30 \%$ of the 5-HTT-positive boutons formed synapses ( $n=10$, partial reconstructions on 6 sections); and in the PVH, $5 \%$ of the boutons formed synapses $(n=19$, partial reconstructions on 8 sections). In Pet1 knock-out mice, asymmetrical synapses were observed in $95 \%$ of the labeled boutons in the BLA $(n=22)$ (Fig. $6 C, D)$, in $70 \%$ of the boutons in the PVT $(n=10)$, and in $53 \%$ of the boutons in the PVH $(n=19)$ (Fig. 6E,F). Postsynaptic targets were dendritic spines or dendritic profiles in the BLA, with an increased frequency of synapses on dendritic shafts in the Pet1 knock-out mice.

Finally, because heterogeneity in the size of the 5-HT axonal varicosities has been reported (Kosofsky and Molliver, 1987; Mamounas et al., 1991), we measured the size of labeled terminals. Boutons in the BLA of Pet1 knock-out mice were significantly larger than controls $\left(0.50 \pm 0.22 \mu \mathrm{m}^{2}\right.$ in Pet1 knock-out, compared to $0.33 \pm 0.12 \mu \mathrm{m}^{2}$ in controls, $p=0.004$, unpaired $t$ test with Welch's correction for unequal variances).

Overall, these observations indicate that a specific subtype of 5-HT axon terminals that have larger terminal boutons and form synaptic junctions are spared in Pet 1 knock-out mice.

\section{Uptake and release of 5-HT in Pet1 knock-out mice}

To analyze the function of the spared 5-HT terminals in Pet1 knock-out mice, binding, uptake, and release properties of synaptosome preparations were obtained from whole brains. As expected, a strong reduction in 5-HT transporter radioligand binding was observed using the specific antagonist $\left[{ }^{3} \mathrm{H}\right]$ citalopram $\left(B_{\max }\right.$ Pet 1 knock-out $=24.6 \pm 6$; controls $=293.7 \pm 7.4$ $\mathrm{fmol} / \mathrm{mg}$ ) (Fig. 7A). Measures of 5-HT uptake showed a parallel decrease (Pet1 knock-out $=29.9 \pm 2.3$; controls $=218.7 \pm 3.4$ $\mathrm{fmol} / \mathrm{min} / \mathrm{mg}$ ) reflecting a reduction in the total uptake capacity 

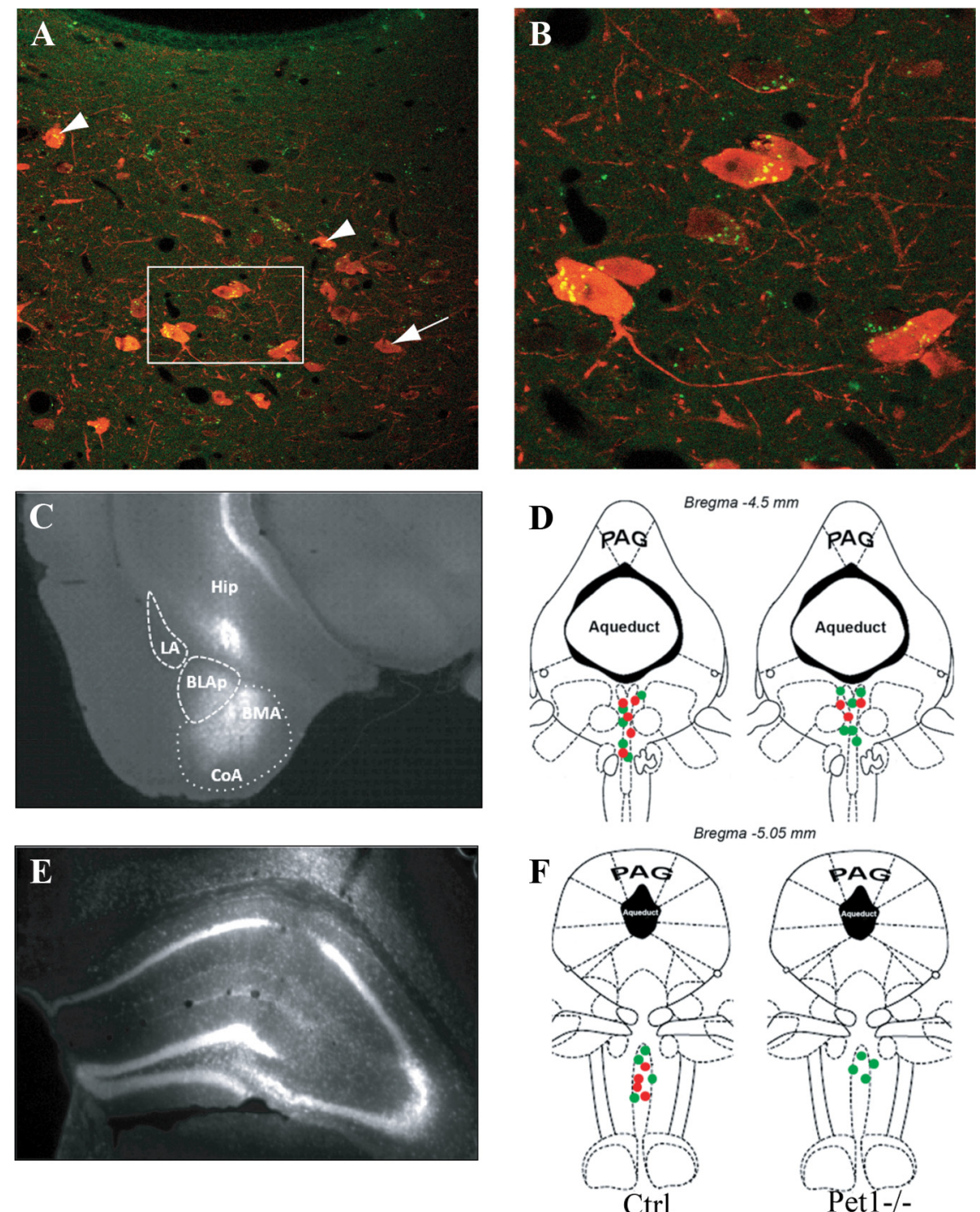

Figure 5. Topography of raphe projections to the amygdala and the hippocampus in Pet1 knock-out mice. $\boldsymbol{A}, \boldsymbol{B}$, Confocal images show back-labeled raphe neurons after fluorogold injections into the amygdala in a control mouse. Arrowheads show double-labeled dorsal raphe neurons. 5 -HT neurons with no retrograde labeling are indicated by arrows. C, Micrograph showing a typical fluorogold injection site into the amygdala; the principal subnuclei are delimited by dashed lines: BLAp, basolateral amygdala, posterior part; BMA, basomedial amygdala; CoA, cortical amygdalar area; LA, lateral amygdala. D, Dorsal raphe neurons projecting to the amygdala are shown at the level where the back-labeled neurons were most abundant. Green dots indicate neurons containing only the retrograde tracer and red dots indicate the retrogradely labeled neurons that were colocalized with 5-HT. E, Typical fluorogold injection into the hippocampus is shown. $\boldsymbol{F}$, Retrogradely labeled neurons from the hippocampus are essentially concentrated in the median raphe in both control and Pet1 $1-/-$. Half of these neurons are $5-\mathrm{HT}$-positive in controls and none in Pet1 $-/-$.

of 5-HT axon terminals (Fig. 7B). However, saturation isotherms revealed no significant differences in the affinity of 5 -HTT $(\mathrm{Km}$ Pet 1 knock-out $=34.6 \pm 3.8$; controls $=31.4 \pm 1.8 \mathrm{fmol} / \mathrm{min} /$ $\mathrm{mg})$. Normalization of 5-HTT uptake with 5-HTT binding revealed no differences in the $V_{\max }$ (Pet1 knock-out $=0.96 \pm 0.03$; controls $=0.87 \pm 0.03$ ), confirming that 5-HTT uptake activity is not altered in Pet1 knock-out remaining neurons.

Finally, we evaluated the ability of the 5-HT releaser MDMA to release 5 -HT from synaptosomes. $\left[{ }^{3} \mathrm{H}\right] 5-\mathrm{HT}$ that was preloaded into brain synaptosomes was fully released in both genotypes $\left(\log \mathrm{EC}_{50}:\right.$ Pet 1 knock-out $=6.26 \pm 0.09$, controls $=6.10 \pm$ 0.11 ) in the presence of MDMA (Fig. 7C).

To evaluate the release properties of 5-HT axon terminals in vivo, we used a D-fenfluramine release assay that has previously been found to induce c-fos activation in the magnocellular nucleus of the $\mathrm{PVH}$, and to activate the adrenocorticotropic axis (Heisler et al., 2007). We tested whether this function is retained in the Pet1 knock-out mice. Nuclear c-Fos staining was counted in the PVH 90 min after an intraperitoneal injection of $\mathrm{D}$-fenfluramine $(10 \mathrm{mg} / \mathrm{kg}$ ) or saline (Fig. 7D). Animals of both genotypes treated with saline showed low levels of $\mathrm{c}$-fos activation, indicating habituation to the injection procedure (Pet1 knock-out $=160 \pm 38$ and control $=127 \pm 45 \mathrm{c}$-Fos + cells $/ \mathrm{mm}^{2}$ ). D-Fenfluramine induced a significant increase of c-Fos + cells in both Pet1 knockout and control mice (Pet1 knock-out $=$ $419 \pm 207$ and control $=491 \pm 180$ c-Fos + cells $/ \mathrm{mm}^{2} ; p=0.014$ and 0.004 , respectively, vs corresponding saline treatment) (Fig. 7E). Finally, we also measured corticosterone plasma levels in response to D-fenfluramine. After a habituation period, animals were injected with D-fenfluramine $10 \mathrm{mg} / \mathrm{kg}$ or saline and killed $1 \mathrm{~h}$ later. D-Fenfluramine increased plasma corticosterone levels, relative to saline treatment, in both Pet1 knock-out and control littermates $(p=0.0045$ and 0.0096 , respectively, vs corresponding saline treatment) (Fig. $7 F$ ). Overall, these data indicate that in Pet1-deficient animals, in vivo 5-HT release occurs normally in those brain areas that are still innervated.

\section{Abnormal fear responses in Pet1 knock-out mice}

Because of the distinctive distribution of remaining 5-HT innervation in fear/ stress related circuits, we conducted a series of behavioral tasks to assess innate anxiety and learned fear responses.

First, we tested Pet1 knock-out mice and control littermates in three exploration-based paradigms to characterize their response to novelty and locomotor function. When placed in an elevated plus maze, Petl knock-out mice explored more the aversive areas of the maze, as revealed by a significant increase in both the percentage of time spent and the percentage of visits into open arms $(p=0.0011$ and 0.0006 , respectively) (Fig. $8 \mathrm{~A}$ ). Sequentially, mice were placed in a novel open arena for $5 \mathrm{~min}$ and exploration of the center area was scored. Pet1 knock-out mice explored the center of the arena more as revealed by a higher percentage of time spent in the center; however, this difference did not reach statistical significance ( $p=0.187$ ) (Fig. $8 B$ ). In the novelty-suppressed feeding test, food-deprived Petl knock-out mice showed a significant decrease in the latency to approach and eat a food pellet located in the center of a brightly illuminated arena $(p=0.0226)$ (Fig. $8 C$ ). To evaluate whether exploration was differentially affected by 
ambient lighting, we placed Pet1 knockout and control mice into circular arenas under dim lighting and evaluated ambulation for a period of $2 \mathrm{~h}$. No significant differences in the total number of beam breaks were found between genotypes $\left(F_{(1,253)}=0.8385, p=0.3693\right)$ (Fig. 8D). The results suggest decreased anxiety in Pet1 knock-out, while showing that these animals possess normal motor functioning.

It should be noted that our finding of increased exploration in the elevated plus maze differs from the initial description of Pet1 knock-out mice (Hendricks et al., 2003), where reduced exploration of the open arm was noted. However, a subsequent study of Pet1 knock-out mice noted increased time in open arm and unchanged open arm entries in the elevated zero maze (Schaefer et al., 2009). These differences can probably be explained by different conditions of housing or experimental conditions used to run the tests (Võikar et al., 2005), as well as by possible divergence in the genetic background.

To investigate changes in learned fear, we evaluated aversive behavior triggered by context and auditory cue conditioning, using three different protocols. For contextual fear responses, animals were placed in the same context where $24 \mathrm{~h}$ earlier they had received three consecutive inescapable footshocks. Freezing behavior was significantly increased in Pet1 knock-out mice $\left(F_{(7,142)}=87.38, p<0.0001\right)$ (Fig. $\left.9 A\right)$. In delay fear conditioning, the conditioned stimulus (tone) was presented with the unconditioned stimulus (shock) and animals were tested in a modified context the next day. Freezing behavior was assessed for $3 \mathrm{~min}$ in the new context and subsequently for 7 min in the presence of the tone. As seen with contextual conditioning, Pet1 knock-out mice showed an enhanced fear response to the tone $\left(F_{(7,84)}=4.63, p=0.0004\right)$ (Fig. $\left.9 B\right)$. In a third modality of this task, a $3 \mathrm{~s}$ interval (trace) was intercalated between the presentation of tone and the delivery of the footshock. When tested $24 \mathrm{~h}$ after training in a modified context, Pet 1 knockout mice showed higher levels of freezing to both new context and the tone $\left(F_{(7,90)}=4.65, p=0.0477\right)$ (Fig. $\left.9 C\right)$. These results demonstrate that Pet1 knock-out mice have enhanced emotional reactivity to learned aversive stimuli. Importantly, exaggerated conditioned fear responses were present after both hippocampal-dependent and -independent learning protocols. This difference cannot be explained by a difference in pain sensitivity as Pet 1 knock-out mice and control littermates presented the same latency to pain response in the hot plate test and similar pain threshold to footshocks (supplemental Fig. S7, available at www.jneurosci.org as supplemental material).

Overall these results indicated that Petl knock-out mice showed increased fear learning in the context of a reduction of fear responses to natural stimuli.

\section{Discussion}

This study revealed the existence of functional subsets of 5-HT neurons, based on differential requirement of the transcription factor Pet1 for the acquisition of a 5-HT identity. Pet1-dependent and Pet1-resistant 5-HT raphe neurons have different morpho-
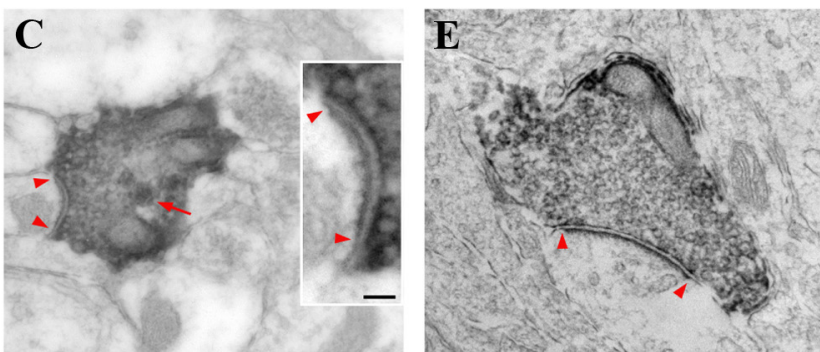

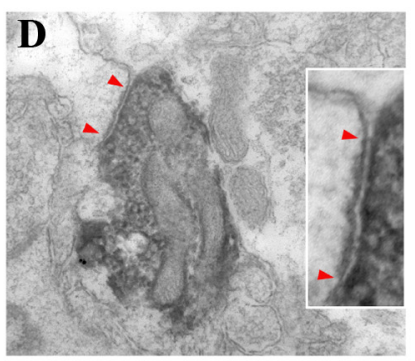

pet1 -/- BLA

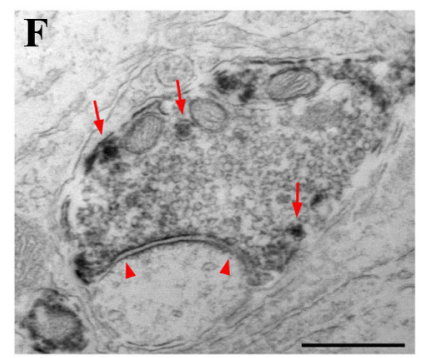

pet1 -/- PVH
Figure 6. Electron micrographs of 5-HTT-labeled axon terminals in control and Pet1 knock-out mice. $\boldsymbol{A}-\boldsymbol{F}$, Micrographs numerous small vesicles and a few large dense vesicles (red arrows). Asymmetric synaptic specializations are marked by Scale bars: $\boldsymbol{A}-\boldsymbol{F}, 500 \mathrm{~nm} ; \boldsymbol{C}, \boldsymbol{D}$, insets, $50 \mathrm{~nm}$.

logical features, including targeting of different brain areas and formation or not of synaptic junctions. The brain regions where serotonergic innervation is spared in Pet 1 knock-out mice outline a functionally coherent set of structures implicated in the control of autonomic and stress responses. The functional consequence was a lowered innate anxiety in conflict tests and increased fear in aversive conditioning paradigms.

\section{Pet1-resistant 5-HT neurons define a subsystem embedded in} the dorsal/median raphe

The subset of 5-HT neurons revealed in Petl knock-out mice transcends the organization into specific raphe cell groups, such as the dorsal and median raphe, while representing a functionally unique system as regards the structures that are targeted. Indeed, Pet1-resistant 5-HT neurons were not confined to a particular raphe nucleus but displayed unique and distinctive target projections, morphology, and synaptic characteristics. Growth characteristics of the Pet1-resistant raphe neurons and the topography of their projections were unchanged, whereas the Pet1dependent raphe 5-HT neurons appeared to lose not only their serotonin phenotype, but also their normal projections to the forebrain, as indicated by the lack of projections in the hippocampus (present study) and reduced projections to the somatosensory cortex (Liu et al., 2010). In this respect, the present observations in Pet1 knock-out mice differ from previous descriptions of altered distribution of 5-HT fibers, in the GAP43 or the protocadherin $\alpha$ knock-out mice for example, which are characterized by an abnormal growth of the ascending raphe neurons (Donovan et al., 2002), or organization of 5-HT axons in target structures (Katori et al., 2009).

Several lines of evidence have previously suggested the existence of heterogeneity among 5-HT neurons within the dorsal and median raphe nuclei (B5-B8). For instance, neurons from different rhombomeres coexist within the raphe subgroups (Jen- 
A

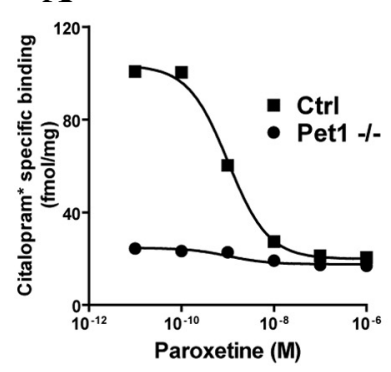

D

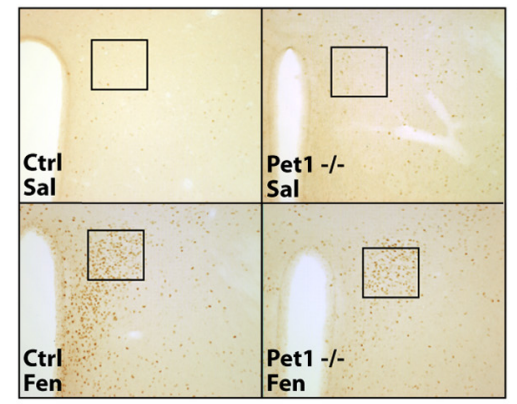

B

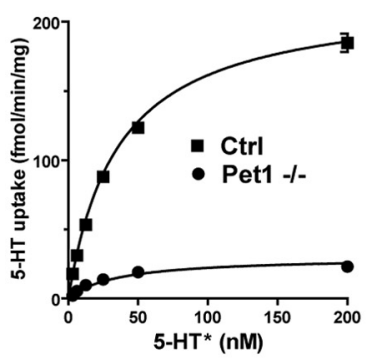

E

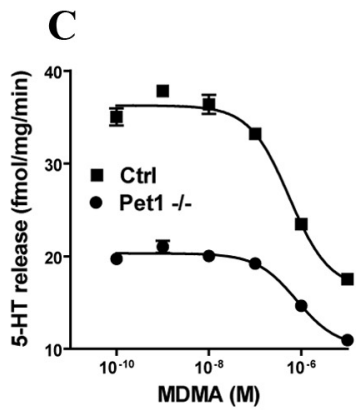

$\mathbf{F}$

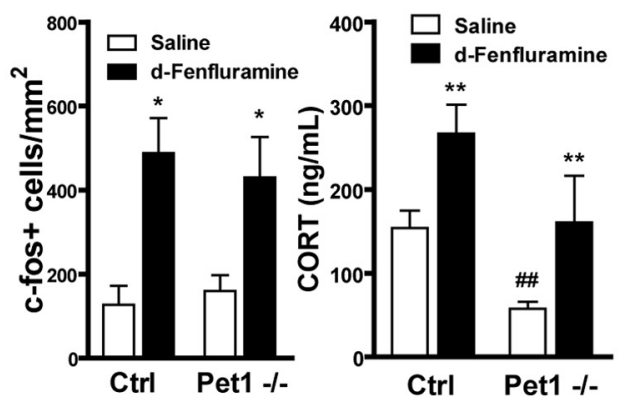

Figure 7. Functional characterization of 5 -HT release in vivo and ex vivo. A, Specific binding of $\left[{ }^{3} \mathrm{H}\right]$ citalopram (selective ligand for 5 -HTT) to whole-brain synaptosome membranes from Pet $1-/-$ and control mice. Maximal number of binding sites is reduced in Pet1 $-/-$ preparations, consistent with reduced levels of 5 -HTT ( $B_{\max }$ Pet1 $-/-=24.6 \pm 6.0$ and control $=293.7 \pm 7.4$ $\mathrm{fmol} / \mathrm{mg}$ ). $\boldsymbol{B}$, Saturation isotherms of 5 -HT uptake by synaptosomes prepared from Pet $1-/-$ and control whole brains. Maximal uptake capacity is reduced in the Pet $1-/-$ preparation $\left(V_{\max }\right.$ Pet $1-/-=29.9 \pm 2.3$ and control $=218.7 \pm 3.4 \mathrm{fmol} / \mathrm{min} /$ $\mathrm{mg})$. C, Release of 5-HT from preloaded synaptosomes by MDMA. Though the loading capacity of both preparations differed in Pet1 knock-out and control preparations, MDMA released 5-HT from both synaptosome preparations in a similar manner (log EC ${ }_{50}$ Pet1 knock-out $=-6.26 \pm 0.09$ and control $=-6.10 \pm 0.11) . D$, A single injection of $D$-fenfluramine $(10 \mathrm{mg} / \mathrm{kg}$, i.p.) activates neurons in the PVH compared to saline. Representative images of c-Fos immunohistochemistry at $10 \times$ magnification. Squares depict the area used for quantification in $\boldsymbol{E}$. $\boldsymbol{E}$, The number of c-Fos-positive cells after D-fenfluramine injection was similar in Pet $1-/-$ and control mice ( ${ }^{*} p<0.05$ vs corresponding saline treatment). $\boldsymbol{F}, \mathrm{D}$-Fenfluramine induces a significant increment in plasma corticosterone in Pet1 knock-out mice and control littermates $\left(F_{(1,20)}=13.27, p=0.0045\right.$ and 0.0096 , respectively, Bonferroni post hoctest after two-way ANOVA, $n=8 /$ group). In addition, a significant genotypic difference was found in response to saline injection $\left(F_{(1,20)}=9.028, p=0.0070\right.$, Bonferroni post hoc test after two-way ANOVA). ${ }^{* *} p<0.01$ versus corresponding saline treatment. ${ }^{\# \#} p<0.01$ saline treatment between genotypes. In all figures, data are expressed as mean \pm SEM.

sen et al., 2008). Anatomical tracing studies showed that the neurons projecting to different telencephalic brain regions were frequently intermixed in a salt-pepper manner in the B5-B8 raphe nuclei, although each of the major subnuclei has broad target specificity (O'Hearn and Molliver, 1984; Imai et al., 1986; Lowry, 2002; Lowry et al., 2008). Relevant to the present observation was the description of a mediodorsal raphe subgroup, projecting to the amygdala and characterized by colocalization with the corticotropin-releasing factor (CRF) (Commons et al., 2003). However, the link between a neurochemical identity and a unique projection pattern remains an unresolved question in mice: in a recent study exploring neuropeptide expression in the raphe, none of the 12 peptides explored, including CRF, was found to be colocalized with 5-HT (Fu et al., 2010). In the future, more systematic analyses of the neurochemical/genomic identity of 5-HT neurons (Wylie et al., 2010) will be needed to extract precise neurochemical taxonomy of the dorsal and median raphe 5-HT neurons.

Clues concerning the genetic diversity of 5-HT raphe neurons may derive from comparing the organization of 5-HT neurons in nonmammalian species in which diverse 5-HT neuronal cell groups are observed outside the raphe. In teleosts, central 5-HT neurons comprise neurons in the hypothalamus and the pretectum (Kaslin and Panula, 2001; Lillesaar et al., 2007, 2009) in addition to the raphe. One possibility is that during the course of evolution, these diverse 5-HT cell groups merged into the raphe cell nucleus in the mammalian brain. Further information about which transcription factors control 5-HT identity in the absence of Pet 1 might help to test this hypothesis. The presence of transcription factors involved in the terminal differentiation of 5-HT neurons, such as Lmx1b and Gata3, in the 5-HT neurons of the Pet1 knock-out suggests that these factors could cooperate with an as yet unknown factor to confer 5-HT identity.

\section{A 5-HT system making synaptic junctions}

5-HT systems are generally thought to be modulatory, and 5-HT release occurs primarily at nonsynaptic sites (Beaudet and Descarries, 1981). However, when serial electron microscopic reconstructions are examined, 5-HT terminal boutons make synaptic contacts in several structures (Descarries et al., 2010). Present observations indicated that a sizable contingent of 5-HT terminals make synaptic junctions in the lateral amygdala, in agreement with previous ultrastructural analysis in the rat lateral amygdala (Muller et al., 2007). Unexpectedly, in Pet1 knock-out mice, we found an increased proportion of synaptic junctions made by the spared 5-HT axon terminals in the amygdala, thalamus, and hypothalamus. These data suggest that 5-HT neurons in Pet1 knock-out mice have the intrinsic capacity for establishing this type of contact.

The nature of the receptors facing synaptic 5-HT junctions remains unresolved, and ultrastructural analyses of the 5-HT receptors are scarce (Cornea-Hébert et al., 1999; Riad et al., 2000). The 5-HT receptors that are present in the areas where 5-HT axon terminals remain in Pet1 knock-out mice may provide interesting clues in this respect. For instance, in the BLA, where 5-HT boutons form synapses, 5-HT2A, 5-HT2C, and 5-HT3 receptors are the main receptors (Wright et al., 1995; McDonald and Mascagni, 2007; Muller et al., 2007). 5-HT2A and 5-HT2C receptors are also strongly expressed in the hypothalamic paraventricular nucleus and intralaminar thalamic nuclei, with preserved innervation in the Pet1 knock-out (Zhang et al., 2002; Heisler et al., 2007).

\section{Stress and autonomic neural circuits are controlled by Pet1-resistant 5-HT neurons}

5-HT is an important component of the central network that provides adaptation to stress (Chaouloff et al., 1999; Lowry et al., 2005). The anatomical circuits underlined by Pet1-resistant 5-HT neurons strikingly correspond to the stress effector pathways. This includes brain structures involved in generating the neuroendocrine, behavioral, and autonomic responses to stressors (Ulrich-Lai and Herman, 2009), such as the amygdala, the $\mathrm{PVH}$, the ventral PAG, and the ventrolateral medulla. Previous studies identified a similar subset of 5-HT neurons projecting to the BLA and hypothalamus that is activated by stress (Lowry et 
A Elevated Plus Maze

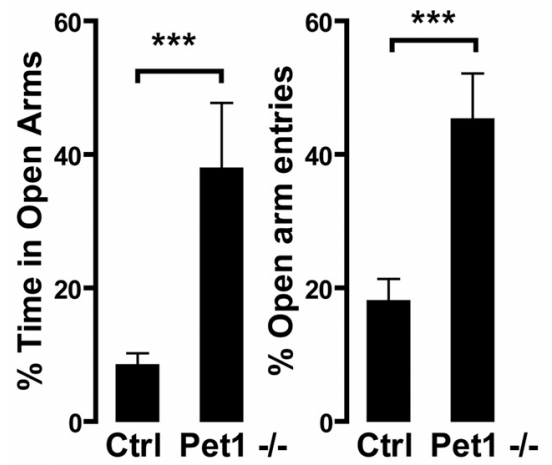

\section{B Open Field}

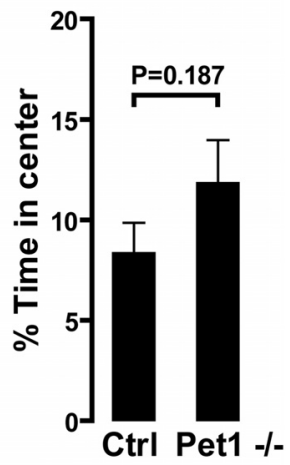

C Novelty-suppressed

\section{Locomotor Activity}

\section{Feeding}
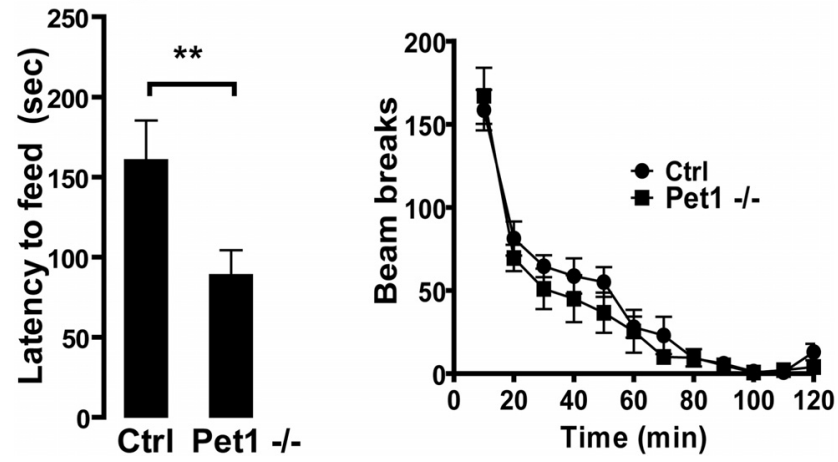

Figure 8. Exploratory behavior of Pet 1 knock-out mice and controls in novel environments. A, Pet1-/ - mice explore the open arms of the maze more than their control littermates as indicated by a higher percentage time spent in open arms and percentage of open arm entries ( ${ }^{* * *} p<0.001$, Student's $t$ test, $n=12$ /group). $B$, The percentage of time spent exploring the center of the open field was not significantly different between groups (Student's $t$ test, $n=$ 12 /group). C, Latency to feed in a novel brightly illuminated arena was significantly lower for Pet $1-/-$ compared to controls ( ${ }^{* *} p<0.01$, Student's $t$ test, $n=11 /$ group). $\boldsymbol{D}$, No differences were found in ambulatory activity between groups. Numbers of light beam breaks are reported in 10 min blocks for a total of $2 \mathrm{~h}$, no significant differences were found between genotypes (two-way ANOVA, $F_{(1,25)}=0.8385, n=13 /$ group). In all figures, data are expressed as mean \pm SEM.

al., 2005). Effectors of the stress response could therefore be under a common control by Pet1-resistant 5-HT neurons.

Similarly, central components of the autonomic relay pathways, such as the nucleus tractus solitarius, the parabrachial nucleus, and the dysgranular insular cortex (Saper, 2002), showed a preserved 5-HT innervation in Pet1 knock-out mice. The relative preservation of 5-HT innervation to autonomic brain centers in these mice explains that changes in autonomic functions like breathing and thermoregulation are relatively mild (Erickson et al., 2007) compared to the more drastic autonomic changes observed in mice with full 5-HT depletion (Hodges et al., 2008).

\section{Consequences on anxiety-related behaviors}

The serotonergic system has long been implicated in the control of anxiety states; however, due to the diversity of 5-HT receptor subtypes, its effects can vary in different brain structures, exerting anxiogenic or anxiolytic actions (Lowry et al., 2005; Lowry and Hale, 2010). Consequently, the functional outcome of an imbalanced 5-HT innervation, such as occurs in the Pet1 knock-out mice, is difficult to predict. The behavioral evaluation performed in this study showed that Pet1 knock-out mice have decreased levels of anxiety in conflict tests involving exploratory behaviors,

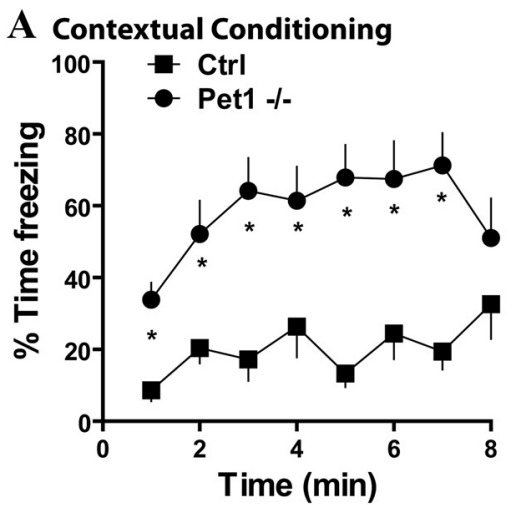

B Delay Conditioning

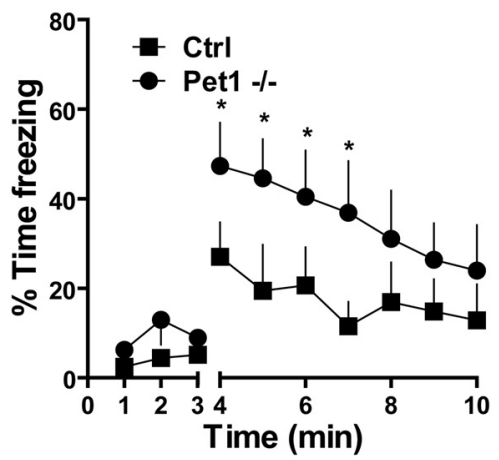

C Trace Conditioning

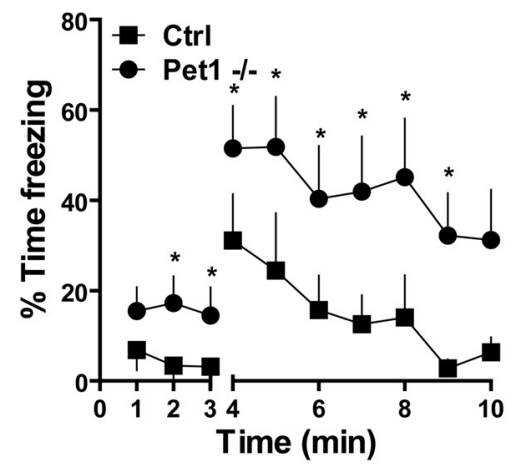

Figure 9. Behavioral responses to learned fear in Pet1 knock-out and control mice. $\boldsymbol{A}$, Conditioned fear responses to context, measured as percentage of time freezing, were exaggerated in Pet $1-/-$ compared to controls $\left({ }^{*} p<0.05\right.$, Bonferroni post hoc test, after two-way ANOVA, $n=12 /$ group). $\boldsymbol{B}$, Delay fear conditioning in Pet1 $-/-$ revealed enhanced fear responses to tone after conditioning with three tone/footshock pairings ( ${ }^{*} p<0.05$, Bonferroni post hoc test, after two-way ANOVA, $n=9 /$ group). The break in the $x$-axis marks the beginning of the tone, and fear responses to the new context were similar for both groups. $\boldsymbol{C}$, For the trace fear conditioning protocol a 3 s interval was added between the tone and the shock. Fear responses were measured in a new context $24 \mathrm{~h}$ after the training and were enhanced in Pet $1-/-{ }^{*} p<0.05$, Bonferroni post hoc test, after two-way ANOVA, $n=8$ /group). The break in the $x$-axis marks the beginning of the tone, and fear responses to the new context were also enhanced in Pet $1-/-$. In all figures, data are expressed as mean \pm SEM.

but enhanced freezing in fear conditioning tests. These observations may appear paradoxical but are in fact consistent with the hypothesis of a dual role of 5-HT in modulating different defensive behaviors. In this model, 5-HT promotes anxiety responses to uncertain potential threats, such as the exploration of a novel environment, whereas it inhibits fear responses in the presence or anticipation of danger, as in fear conditioned paradigms (Graeff and Zangrossi, 2010). Anxiogenic effects of 5-HT in unconditioned anxiety tasks occur mainly through the innervation of forebrain areas, such as the medial prefrontal cortex and hip- 
pocampus. These areas showed profound 5-HT depletion in Pet1 knock-out mice, which would explain the anxiolytic phenotype in conflict exploratory tests. Accordingly, other genetic models of 5-HT depletion have shown a similar anxiolytic-like phenotype in these tests (Dai et al., 2008; Kim et al., 2009). Conversely, 5-HT inhibits fear responses through the targeting of specific amygdala and PAG subnuclei. In Pet1 knock-out mice, 5-HT projections to the BLA, central amygdala, and ventral PAG are mostly spared, indicating that fear responses should not be affected. However, recent evidence suggests that 5-HT receptor subtypes may be differently expressed throughout amygdala cell types. Thus, while 5-HT2A receptors are expressed in parvalbuminpositive GABAergic neurons (Jiang et al., 2009), 5-HT2C receptors are more widely expressed in the amygdala (Wright et al., 1995), consistent with expression in projection neurons. Electrophysiological recordings showed that activation of 5-HT2A receptors in GABAergic interneurons induces an increase in the frequency of inhibitory events on glutamatergic projecting neurons (Stutzmann et al., 1998; Rainnie, 1999; Stein et al., 2000). Importantly, exposure to stress results in an altered balance of 5-HT2A/5-HTC expression levels in the amygdala, resulting in hyperexcitability of the amygdaloid circuits (Jiang et al., 2009). Therefore, it is possible that Pet1-dependent and Pet1-resistant serotonin raphe neurons target different cell types in the amygdala, and that removal of one of these systems creates an imbalance that results in exaggerated fear responses.

\section{Possible relevance to neurological disorders}

Our study opens the possibility that genes controlling the differentiation of subpopulations of 5-HT neurons could be implicated as risk factors in neurological or psychiatric diseases. Selective vulnerability of monoamine systems in neurodegenerative diseases is well substantiated in the case of the dopaminergic systems. In Parkinson's disease and related models, the differential vulnerability of mesolimbic versus mesostriatal system has been extensively documented (German et al., 1989; Parent and Lavoie, 1993; Gaspar et al., 1994), and may in part be explained by transcriptional regulation (Alavian et al., 2008). Similarly, 5-HT neurons have been shown to be selectively susceptible to the neurotoxin methamphetamine, which causes the loss of the most abundant 5-HT fine axon terminal boutons, whereas the less abundant large terminal boutons are spared (Kosofsky and Molliver, 1987; Hornung et al., 1990). Thus, establishing similar links between the genetic heterogeneity of the 5-HT neurons and selective vulnerability to disease will be a particularly interesting endeavor, given the number of pathologies linked to 5 -HT dysfunction.

\section{References}

Abrams JK, Johnson PL, Hollis JH, Lowry CA (2004) Anatomic and functional topography of the dorsal raphe nucleus. Ann NY Acad Sci 1018:46-57.

Abumaria N, Ribic A, Anacker C, Fuchs E, Flügge G (2008) Stress upregulates TPH1 but not TPH2 mRNA in the rat dorsal raphe nucleus: identification of two TPH2 mRNA splice variants. Cell Mol Neurobiol 28:331-342.

Adell A, Casanovas JM, Artigas F (1997) Comparative study in the rat of the actions of different types of stress on the release of 5-HT in raphe nuclei and forebrain areas. Neuropharmacology 36:735-741.

Alavian KN, Scholz C, Simon HH (2008) Transcriptional regulation of mesencephalic dopaminergic neurons: the full circle of life and death. Mov Disord 23:319-328.

Beaudet A, Descarries L (1981) The fine structure of central serotonin neurons. J Physiol Paris 77:193-203.
Chaouloff F, Berton O, Mormède P (1999) Serotonin and stress. Neuropsychopharmacology 21:28S-32S.

Commons KG, Connolley KR, Valentino RJ (2003) A neurochemically distinct dorsal raphe-limbic circuit with a potential role in affective disorders. Neuropsychopharmacology 28:206-215.

Cordes SP (2005) Molecular genetics of the early development of hindbrain serotonergic neurons. Clin Genet 68:487-494.

Cornea-Hébert V, Riad M, Wu C, Singh SK, Descarries L (1999) Cellular and subcellular distribution of the serotonin 5-HT2A receptor in the central nervous system of adult rat. J Comp Neurol 409:187-209.

Crestani F, Lorez M, Baer K, Essrich C, Benke D, Laurent JP, Belzung C, Fritschy JM, Lüscher B, Mohler H (1999) Decreased GABAA-receptor clustering results in enhanced anxiety and a bias for threat cues. Nat Neurosci 2:833-839.

Dai J-X, Han H-L, Tian M, Cao J, Xiu J-B, Song N-N, Huang Y, Xu T-L, Ding Y-Q, Xu L (2008) Enhanced contextual fear memory in central serotonin-deficient mice. Proc Natl Acad Sci U S A 105:11981-11986.

Descarries L, Riad M, Parent M (2010) Ultrastructure of the serotonin innervation in the mammalian central nervous system. In: Handbook of the behavioural neurobiology of serotonin (Müller CP, Jacobs BL, eds). San Diego: Academic.

Dieudonné S, Dumoulin A (2000) Serotonin-driven long-range inhibitory connections in the cerebellar cortex. J Neurosci 20:1837-1848.

Donovan SL, Mamounas LA, Andrews AM, Blue ME, McCasland JS (2002) GAP-43 is critical for normal development of the serotonergic innervation in forebrain. J Neurosci 22:3543-3552.

Erickson JT, Shafer G, Rossetti MD, Wilson CG, Deneris ES (2007) Arrest of 5HT neuron differentiation delays respiratory maturation and impairs neonatal homeostatic responses to environmental challenges. Respir Physiol Neurobiol 159:85-101.

Fu W, Le Maître E, Fabre V, Bernard JF, David Xu ZQ, Hökfelt T (2010) Chemical neuroanatomy of the dorsal raphe nucleus and adjacent structures of the mouse brain. J Comp Neurol 518:3464-3494.

Fuxe K, Dahlström A, Höistad M, Marcellino D, Jansson A, Rivera A, DiazCabiale Z, Jacobsen K, Tinner-Staines B, Hagman B, Leo G, Staines W, Guidolin D, Kehr J, Genedani S, Belluardo N, Agnati LF (2007) From the Golgi-Cajal mapping to the transmitter-based characterization of the neuronal networks leading to two modes of brain communication: wiring and volume transmission. Brain Res Rev 55:17-54.

Gaspar P, Ben Jelloun N, Febvret A (1994) Sparing of the dopaminergic neurons containing calbindin-D28k and of the dopaminergic mesocortical projections in weaver mutant mice. Neuroscience 61:293-305.

German DC, Manaye K, Smith WK, Woodward DJ, Saper CB (1989) Midbrain dopaminergic cell loss in Parkinson's disease: computer visualization. Ann Neurol 26:507-514.

Graeff FG, Zangrossi H Jr (2010) The dual role of serotonin in defense and the mode of action of antidepressants on generalized anxiety and panic disorders. Cent Nerv Syst Agents Med Chem 10:207-217.

Gray EG, Whittaker VP (1962) The isolation of nerve endings from brain: an electron-microscopic study of cell fragments derived by homogenization and centrifugation. J Anat 96:79-88.

Heisler LK, Pronchuk N, Nonogaki K, Zhou L, Raber J, Tung L, Yeo GS, O’Rahilly S, Colmers WF, Elmquist JK, Tecott LH (2007) Serotonin activates the hypothalamic-pituitary-adrenal axis via serotonin $2 \mathrm{C}$ receptor stimulation. J Neurosci 27:6956-6964.

Hendricks T, Francis N, Fyodorov D, Deneris ES (1999) The ETS domain factor Pet-1 is an early and precise marker of central serotonin neurons and interacts with a conserved element in serotonergic genes. J Neurosci 19:10348-10356.

Hendricks TJ, Fyodorov DV, Wegman LJ, Lelutiu NB, Pehek EA, Yamamoto B, Silver J, Weeber EJ, Sweatt JD, Deneris ES (2003) Pet-1 ETS gene plays a critical role in 5-HT neuron development and is required for normal anxiety-like and aggressive behavior. Neuron 37:233-247.

Herzog E, Gilchrist J, Gras C, Muzerelle A, Ravassard P, Giros B, Gaspar P, El Mestikawy S (2004) Localization of VGLUT3, the vesicular glutamate transporter type 3, in the rat brain. Neuroscience 123:983-1002.

Hioki H, Nakamura H, Ma YF, Konno M, Hayakawa T, Nakamura KC, Fujiyama F, Kaneko T (2010) Vesicular glutamate transporter 3-expressing nonserotonergic projection neurons constitute a subregion in the rat midbrain raphe nuclei. J Comp Neurol 518:668-686.

Hodges MR, Tattersall GJ, Harris MB, McEvoy SD, Richerson DN, Deneris ES, Johnson RL, Chen ZF, Richerson GB (2008) Defects in breathing 
and thermoregulation in mice with near-complete absence of central serotonin neurons. J Neurosci 28:2495-2505.

Hornung JP, Fritschy JM, Törk I (1990) Distribution of two morphologically distinct subsets of serotoninergic axons in the cerebral cortex of the marmoset. J Comp Neurol 297:165-181.

Imai H, Steindler DA, Kitai ST (1986) The organization of divergent axonal projections from the midbrain raphe nuclei in the rat. J Comp Neurol 243:363-380.

Iyo AH, Porter B, Deneris ES, Austin MC (2005) Regional distribution and cellular localization of the ETS-domain transcription factor, FEV, mRNA in the human postmortem brain. Synapse 57:223-228.

Jacobs BL, Azmitia EC (1992) Structure and function of the brain serotonin system. Physiol Rev 72:165-229.

Jensen P, Farago AF, Awatramani RB, Scott MM, Deneris ES, Dymecki SM (2008) Redefining the serotonergic system by genetic lineage. Nat Neurosci 11:417-419.

Jiang X, Xing G, Yang C, Verma A, Zhang L, Li H (2009) Stress impairs 5-HT2A receptor-mediated serotonergic facilitation of GABA release in juvenile rat basolateral amygdala. Neuropsychopharmacology 34:410-423.

Kaslin J, Panula P (2001) Comparative anatomy of the histaminergic and other aminergic systems in zebrafish (Danio rerio). J Comp Neurol 440:342-377.

Katori S, Hamada S, Noguchi Y, Fukuda E, Yamamoto T, Yamamoto H, Hasegawa S, Yagi T (2009) Protocadherin- $\alpha$ family is required for serotonergic projections to appropriately innervate target brain areas. J Neurosci 29:9137-9147.

Kim JC, Cook MN, Carey MR, Shen C, Regehr WG, Dymecki SM (2009) Linking genetically defined neurons to behavior through a broadly applicable silencing allele. Neuron 63:305-315.

Kirby LG, Allen AR, Lucki I (1995) Regional differences in the effects of forced swimming on extracellular levels of 5-hydroxytryptamine and 5-hydroxyindoleacetic acid. Brain Res 682:189-196.

Kosofsky BE, Molliver ME (1987) The serotoninergic innervation of cerebral cortex: different classes of axon terminals arise from dorsal and median raphe nuclei. Synapse 1:153-168.

Lacoste B, Riad M, Descarries L (2006) Immunocytochemical evidence for the existence of substance P receptor (NK1) in serotonin neurons of rat and mouse dorsal raphe nucleus. Eur J Neurosci 23:2947-2958.

Lidov H, Grzanna R, Molliver M (1980) The serotonin innervation of the cerebral cortex in the rat - an immunohistochemical analysis. Neuroscience 5:207-227.

Lillesaar C, Tannhäuser B, Stigloher C, Kremmer E, Bally-Cuif L (2007) The serotonergic phenotype is acquired by converging genetic mechanisms within the zebrafish central nervous system. Dev Dyn 236:1072-1084.

Lillesaar C, Stigloher C, Tannhäuser B, Wullimann MF, Bally-Cuif L (2009) Axonal projections originating from raphe serotonergic neurons in the developing and adult zebrafish, Danio rerio, using transgenics to visualize raphe-specific petl expression. J Comp Neurol 512:158-182.

Liu C, Maejima T, Wyler SC, Casadesus G, Herlitze S, Deneris ES (2010) Pet-1 is required across different stages of life to regulate serotonergic function. Nat Neurosci 13:1190-1198.

Lowry CA (2002) Functional subsets of serotonergic neurones: implications for control of the hypothalamic-pituitary-adrenal axis. J Neuroendocrinol 14:911-923.

Lowry CA, Hale MW (2010) Serotonin and the neurobiology of anxious states. In: Handbook of the behavioural neurobiology of serotonin (Müller CP, Jacobs BL, eds), pp 379-399. San Diego: Academic.

Lowry CA, Johnson PL, Hay-Schmidt A, Mikkelsen J, Shekhar A (2005) Modulation of anxiety circuits by serotonergic systems. Stress 8:233-246.

Lowry CA, Evans AK, Gasser PJ, Hale MW, Staub DR, Shekhar A (2008) Topographic organization and chemoarchitecture of the dorsal raphe nucleus and the median raphe nucleus. In: Serotonin and sleep: molecular, functional and clinical aspects (Monti JM, Pandi-Perumal SR, Jacobs BL, Nutt DJ, eds), pp 25-60. Switzerland: Birhauser Verlag.

Lucki I (1998) The spectrum of behaviors influenced by serotonin. Biol Psychiatry 44:151-162.

Mamounas LA, Mullen CA, O’Hearn E, Molliver ME (1991) Dual serotoninergic projections to forebrain in the rat: morphologically distinct
5-HT axon terminals exhibit differential vulnerability to neurotoxic amphetamine derivatives. J Comp Neurol 314:558-586.

McDonald AJ, Mascagni F (2007) Neuronal localization of 5-HT type 2A receptor immunoreactivity in the rat basolateral amygdala. Neuroscience 146:306-320.

Muller JF, Mascagni F, McDonald AJ (2007) Serotonin-immunoreactive axon terminals innervate pyramidal cells and interneurons in the rat basolateral amygdala. J Comp Neurol 505:314-335.

Nakamura K, Sugawara Y, Sawabe K, Ohashi A, Tsurui H, Xiu Y, Ohtsuji M, Lin QS, Nishimura H, Hasegawa H, Hirose S (2006) Late developmental stage-specific role of tryptophan hydroxylase 1 in brain serotonin levels. J Neurosci 26:530-534.

O'Hearn E, Molliver ME (1984) Organization of raphe-cortical projections in rat: a quantitative retrograde study. Brain Res Bull 13:709-726.

Parent A, Lavoie B (1993) The heterogeneity of the mesostriatal dopaminergic system as revealed in normal and parkinsonian monkeys. Adv Neurol 60:25-33.

Paxinos G, Franklin K (2001) The mouse brain in stereotaxic coordinates, Ed 2. San Diego: Academic.

Pfaar H, von Holst A, Vogt Weisenhorn DM, Brodski C, Guimera J, Wurst W (2002) mPet-1, a mouse ETS-domain transcription factor, is expressed in central serotonergic neurons. Dev Genes Evol 212:43-46.

Pickel VM, Chan J (1999) Ultrastructural localization of the serotonin transporter in limbic and motor compartments of the nucleus accumbens. J Neurosci 19:7356-7366.

Rainnie DG (1999) Serotonergic modulation of neurotransmission in the rat basolateral amygdala. J Neurophysiol 82:69-85.

Riad M, Garcia S, Watkins KC, Jodoin N, Doucet E, Langlois X, el Mestikawy S, Hamon M, Descarries L (2000) Somatodendritic localization of 5-HT1A and preterminal axonal localization of 5-HT1B serotonin receptors in adult rat brain. J Comp Neurol 417:181-194.

Saper CB (1995) Central autonomic system. In: The rat nervous system, Ed 2 (Paxinos G, ed), pp 107-135. San Diego: Academic.

Saper CB (2002) The central autonomic nervous system: conscious visceral perception and autonomic pattern generation. Annu Rev Neurosci 25:433-469.

Schaefer TL, Vorhees CV, Williams MT (2009) Mouse plasmacytomaexpressed transcript 1 knock out induced 5-HT disruption results in a lack of cognitive deficits and an anxiety phenotype complicated by hypoactivity and defensiveness. Neuroscience 164:1431-1443.

Scott MM, Krueger KC, Deneris ES (2005) A differentially autoregulated Pet-1 enhancer region is a critical target of the transcriptional cascade that governs serotonin neuron development. J Neurosci 25:2628-2636.

Stein C, Davidowa H, Albrecht D (2000) 5-HT(1A) receptor-mediated inhibition and 5-HT(2) as well as 5-HT(3) receptor-mediated excitation in different subdivisions of the rat amygdala. Synapse 38:328-337.

Stutzmann GE, McEwen BS, LeDoux JE (1998) Serotonin modulation of sensory inputs to the lateral amygdala: dependency on corticosterone. J Neurosci 18:9529-9538.

Ulrich-Lai YM, Herman JP (2009) Neural regulation of endocrine and autonomic stress responses. Nat Rev Neurosci 10:397-409.

Varga V, Losonczy A, Zemelman BV, Borhegyi Z, Nyiri G, Domonkos A, Hangya B, Holderith N, Magee JC, Freund TF (2009) Fast synaptic subcortical control of hippocampal circuits. Science 326:449-453.

Võikar V, Polus A, Vasar E, Rauvala H (2005) Long-term individual housing in C57BL/6J and DBA/2 mice: assessment of behavioral consequences. Genes Brain Behav 4:240-252.

Wright DE, Seroogy KB, Lundgren KH, Davis BM, Jennes L (1995) Comparative localization of serotonin $1 \mathrm{~A}, 1 \mathrm{C}$, and 2 receptor subtype mRNAs in rat brain. J Comp Neurol 351:357-373.

Wylie CJ, Hendricks TJ, Zhang B, Wang L, Lu P, Leahy P, Fox S, Maeno H, Deneris ES (2010) Distinct transcriptomes define rostral and caudal serotonin neurons. J Neurosci 30:670-684.

Zhang Y, Damjanoska KJ, Carrasco GA, Dudas B, D'Souza DN, Tetzlaff J, Garcia F, Hanley NR, Scripathirathan K, Petersen BR, Gray TS, Battaglia G, Muma NA, Van de Kar LD (2002) Evidence that 5-HT2A receptors in the hypothalamic paraventricular nucleus mediate neuroendocrine responses to (-)DOI. J Neurosci 22:9635-9642. 